\title{
Exploring the potential of black gram (Vigna mungo) flour as a fat replacer in biscuits with improved physicochemical, microstructure, phytochemicals, nutritional and sensory attributes
}

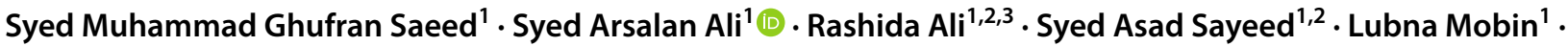 \\ Raheel Ahmed ${ }^{3}$
}

Received: 12 August 2020 / Accepted: 29 October 2020

(c) Springer Nature Switzerland AG 2020, corrected publication 2021

\begin{abstract}
High fat intake is associated with various health disorders. Therefore, there have been continued efforts to reduce the fat content in food products and replace it with various fat replacers. In the present study, the effect of black gram (Vigna mungo) flour (BGF) as a fat replacer in biscuits at different concentrations $(10,15,20,25$, and 50\% w/w) was explored. The proximate functional, rheological, microstructural, phytochemical, antioxidant, nutritional, and sensory properties of the flour and biscuits samples were evaluated. The inclusion of BGF in the formulation of biscuit altered dough rheology significantly $(P \leq 0.05)$. The gluten content of the flour blends decreases with the addition of BGF, while the increased water absorption (145.60-162.24\%) increases in the gluten development time, and it was increased from $1.67 \mathrm{~min}$ for control (without BGF) to 11.50 min for $50 \%$ BGF substitution. Furthermore, the addition of BGF resulted in a significant $(P \leq 0.05)$ decrease in setback (958-162 cP) and breakdown (7561-894 cP) viscosities. The scanning electron microscopy of biscuits dough elaborated after fat replacement at different levels showing that evenly distribution of starch granule was disrupted, and the gluten matrix was often ruptured. Total phenolic content (TPC) and total flavonoid content (TFC) of flour samples increased from 16.73-177.16 mg Gallic acid/100 g dw and 18.56-421.60 mg Catechin/100 dw, respectively. Baking decreased the TPC, whereas TFC was increased in comparison to flour blends. Similarly, biscuits also showed an increment in their antioxidant activity. The crude fiber and protein contents of BGF-WF (Wheat flour) biscuits improved from 0.21 to $3.01 \%$ and 15.20 to $26.85 \%$, respectively. Sensory and textural performance exhibited that the biscuits were acceptable for fat replacement up to $15 \%$ BGF. Based on this study, BGF may be promoted and commercialized as a highly antioxidative and nutritive edible flour, which can be prospectively used in the development of natural fat replacers, nutraceuticals, and functional foods. The current approach also enhances the economy of legumes processing industries by providing value to BGFs.
\end{abstract}

Keywords Antioxidant activity · Dough rheology · Fat replacer · Functional properties · Black gram flour · Sensorial analysis

Syed Arsalan Ali, 786syedarsalanali@gmail.com | 'Department of Food Science and Technology, University of Karachi, Main University Road, Karachi, Sindh 75270, Pakistan. ${ }^{2}$ Department of Food Science and Technology, Jinnah Women University, 5C, Block 5 Nazimabad, Karachi City, Sindh 74600, Pakistan. ${ }^{3}$ English Biscuit Manufacturers Private Limited, Karachi, Sindh, Pakistan.

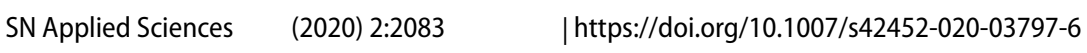




\section{Introduction}

The demand for functional food products is gaining significant attention from consumers due to their healthpromoting benefits [1]. Generally, biscuits are widely used as snacks to overcome short-term energy depletion. Consuming functional biscuits may have added health benefits for consumers, such as recommended daily intake (RDI) fulfillment, improving general wellbeing, and minimizing the consumption of nutritional supplements. Moreover, biscuits available in the market are generally manufactured from all-purpose wheat flour and hence lack essential amino acids, fatty acids, vitamins, minerals, and dietary fibers [2]. Furthermore, bakery products, including biscuits, are rich in fat content [3]. Fat in biscuit formulations has a multifaceted function and is a principal ingredient responsible for softness, keeping quality, flavor, and texture of biscuits [4]. On the other hand, consumption of a high amount of fat is linked with many health issues such as high blood cholesterol, cardiovascular diseases, diabetes, cancer, and obesity [2]. Therefore, there is a need to replace fat with an ingredient which can also improve the quality and nutritional value of biscuits.

Fat replacers or fat mimetics are may be carbohydrate, protein, and fiber-based. A variety of fat replacers are available, such as the modified starches, celluloses, cellulose derivatives, microcrystalline cellulose, gelatin, pectin, gums, dietary fibers, micro-particulate proteins and, etc. [5]. However, all of them perform similar functions as fat in a food system [6]. The functions of fat mimetics in a food system include diverse type activities, such as they provide flavor, palatability, tenderness, creaminess, viscosity, opacity, lubricity, resistance to other than fat-molecular interactions, ingredients coating, etc. [7]. Some of these properties of fat mimetics are responsible for weak gluten network, which is desirable in biscuits manufacturing. The unique function of the fat is to impart flavor; however, fat mimetics do not provide flavor similar to fat and generally have more excellent water absorption. Therefore, emulsifiers are required in case of the incorporation of lipophilic flavor in the product [8]. The high caloric density of fat $(9 \mathrm{kcal} / \mathrm{g})$ develops satiety in foods, the feeling of satiety is achieved by the diet rich in fibers as fibers have the ability to absorb the excess of water and swells, providing a sense of fullness after the meal which is considered as one of the attributes of fibers to mimic fat.

Black gram (BG), also known as Vigna mungo, belonging to the Leguminoseae family, is widely used in Pakistan as a therapeutic ingredient [2]. The BG contains lesser amount of fat (5.13\%) and a significant quantity of dietary fibers, proteins, vitamins, and minerals [9]. Furthermore, polar compounds in BG generates lubricity and creaminess in bakery products similar to those found in full-fat products [10]. In contrast, the presence of the non-polar compounds provides functional characteristics of fat to BG, such as lipid-soluble flavor carrying capacity [10]. Polysaccharides like gums, starches, pectin, and cellulose are capable of binding water and, therefore, can serve as thickeners or gelling agents and therefore as fat replacers in foods in view of the fact that high viscosity and gel formation are the desired properties in a fat substitute [11]. Some of the components of BG possess functional properties such as the aqueous solubility, swelling, water binding, foaming, gelation, and emulsifying capacity [9] which may make it a good fat mimetic in food products.

In search of fat-replacer, Roman et al. [12] incorporated emulsifiers containing wheat flour paste in cake formulation. Polydextrose, maltodextrins, and simplesse were also investigated to replace fat in biscuits [13]. Peanut butter biscuits were manufactured by Adair et al. [14], which contained mung bean as a fat replacer. Rankin and Bingham [15] utilized pureed white bean as a fat substitute in the biscuits. The present study is first of its kind where BG flour (BGF) was evaluated as a fat replacer in biscuits by characterizing rheological, functional, physicochemical, morphological, textural, dimensional, nutritional and sensory features.

\section{Materials and methods}

\subsection{Collection of raw materials}

Commercial wheat flour (WF) was received from Graib Sons Private Limited, Karachi. Icing sugar, black gram (BG) seeds, whole fresh egg, and salt were purchased from the local market of Karachi. Semi-solid fat (banaspati ghee/ shortening/ partially unsaturated fat) was purchased from Paracha Mills Ghee Textile Unit, Karachi. Glucose, baking powder, and soy lecithin were obtained from Sulop Chemicals located in Karachi.

\subsection{Chemicals}

All chemicals used for the study were analytical reagent grade procured from Dae-Jung Chemicals, South Korea and Sigma-Aldrich, Germany.

\subsection{Preparation of Black gram flour and BGF-WF blends}

The whole BG seeds were sorted manually to eliminate the impurities and foreign material. Pretreatment was applied to whole BG seeds to deactivate enzymes. Whole BG seeds were heated at $88^{\circ} \mathrm{C}$ for $10 \mathrm{~min}$ in a hot-air oven 
(DSO-300 D, digisystem laboratory instruments, Taiwan). Ajila and Rao [16] had demonstrated that $80^{\circ} \mathrm{C}$ dry heat for 10 min inactivated different enzymes found in BG extracts. About $5 \mathrm{~kg}$ whole BG seeds were milled in a laboratory hand miller (3100, Perten Instruments) and sieved under $60 \mu$ mesh screen (Fig. 1). The BGF was added to wheat flour (WF) in 10,15,20,25, and 50\% (w/w) concentrations, which covers the standard range of fat contents used in biscuits. Sample flour contained various WF to BGF ratios indicated as BGF-WF blends.

\subsection{Proximate composition of flour}

Moisture, ash, and protein content of different concentrations of BGF incorporated in wheat flour, were analyzed according to the AACC Method [17]. Wet gluten (WG), dry gluten (DG), gluten index (Gl), and total gluten content (TGC) were estimated by Glutomatic (2200, Perten Instruments, USA) according to the AACC Method [17]. Each sample was tested in triplicate for proximate analysis.

\subsection{Functional properties of flour blends}

\subsubsection{Swelling power}

Abebe et al. [18] method was used for the estimation of swelling power (SP) of flour blends. Approximately $1 \mathrm{~g}$ of the flour was added along with the $10 \mathrm{~mL}$ of distilled water in a centrifuge tube $(20 \mathrm{~mL})$. The blend was then heated for 30 min at $80^{\circ} \mathrm{C}$ in a water bath. After cooling at room temperature, the tube was centrifuged for $15 \mathrm{~min}$ at $1000 \times \mathrm{g}$, and then subsequent paste was determined for SP.

The SP was calculated from the following formula:

Swelling power $=$ Weight of the sediment paste $(g) /$

$$
\text { Weight of dry sample (g) }
$$

\subsubsection{Water absorption and oil binding capacities}

Water absorption capacity (WAC) and oil binding capacity $(\mathrm{OBC})$ were determined as proposed by Abebe et al. [18]. For WAC, distilled water $(10 \mathrm{~mL})$ was mixed with flour $(1 \mathrm{~g})$, vortexed for $2 \mathrm{~min}$, and finally centrifuged at $2200 \times \mathrm{g}$ for $20 \mathrm{~min}$. The supernatant was decanted, and the residual pellets were weighed and analyzed for WAC. The same procedure was done to determine the $\mathrm{OBC}$ by using soya bean oil $(10 \mathrm{~mL})$.

\subsubsection{Emulsion capacity and stability}

Emulsion capacity (EC) and stability (ES) were evaluated by using the method of Yasumatsu et al. [19]. $1 \mathrm{~g}$ of sample, deionized water $(5 \mathrm{~mL})$ and soya bean oil $(5 \mathrm{~mL})$ was added. Vortexed for a min, homogenized for $2 \mathrm{~min}$ and centrifuged at $1100 \times \mathrm{g}$ for $5 \mathrm{~min}$. The volume of the emulsified phase and total contents of the tube were measured. The EC was calculated as follows:

Emulsion Capacity\%

$$
=\frac{\text { Volume of the emulsified layer }}{\text { Total volume of sample in the centrifuge tube }} \times 100
$$

The same sample was used for both EC and ES analysis. Briefly, the sample was placed in a water bath at $80^{\circ} \mathrm{C}$ for $30 \mathrm{~min}$, followed by cooling under running tap water for $15 \mathrm{~min}$ and then centrifuged at $2000 \times \mathrm{g}$ for $15 \mathrm{~min}$. ES was quantified as follows:

$$
\begin{aligned}
& \text { Emulsion Stability } \% \\
& \qquad=\frac{\text { Volume of remaining emulsified phase }}{\text { Original emulsion volume before heating }} \times 100
\end{aligned}
$$

\subsubsection{Solvent retention capacity (SRC)}

Solvent retention capacities of flour samples were evaluated by AACC Method 56-11 [17]. The calculated amount
Fig. 1 Whole Black gram seeds and its flour

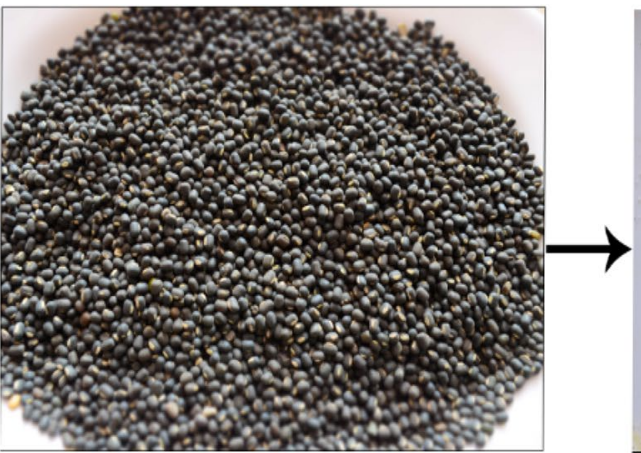

Whole black gram seeds

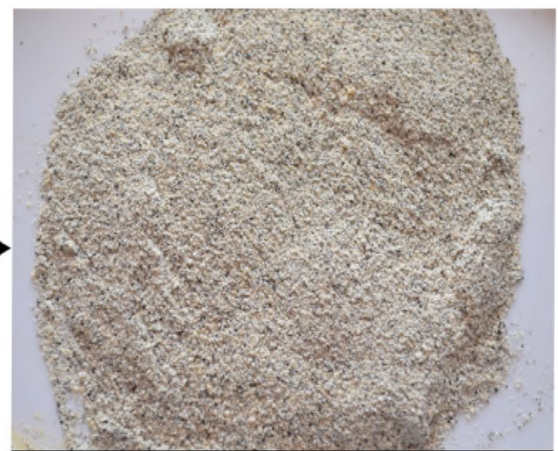

Black gram flour 
of flour samples weighted in $50 \mathrm{~mL}$ centrifuge tubes. Then, an appropriate amount of the respective solvent such as deionized water, sucrose solution $50 \%(\mathrm{w} / \mathrm{w})$, sodium carbonate solution $5 \%(\mathrm{w} / \mathrm{w})$, and lactic acid solution $5 \%$ $(\mathrm{w} / \mathrm{w})$ were added separately to each tube. The mixtures were shaken vigorously for $5 \mathrm{~s}$ at intervals of $5,10,15$, and $20 \mathrm{~min}$. After $20 \mathrm{~min}$, the tubes were centrifuged at $1000 \times g$ for $15 \mathrm{~min}$. Supernatant decanted, and tubes were kept at $90^{\circ}$ angle for $10 \mathrm{~min}$ on a paper towel. The weight of the gel was then determined.

SRC\% was calculated using the following formula:

$$
\begin{aligned}
\text { SRC\% }= & {[(\text { gel weight }(\mathrm{g}) / \text { flour weight }(\mathrm{g}))-1] } \\
& \times[86 /(100-\text { flour moisture })] \times 100
\end{aligned}
$$

\subsection{Empirical rheological methods}

\subsubsection{Dough rheological properties during mixing}

The effect of different concentrations of added BGF on the rheological properties of WF was studied using a Farinograph (300 g mixer bowl, Brabender OHG, Duisburg, Germany), as per the AACC Method 54-21 [17]. The parameters measured included water absorption (WA), dough development time (DDT), dough stability time (DST), and farinograph quality number (FQN).

\subsubsection{Dough viscometric properties}

The pasting properties were analyzed by Micro ViscoAmylo-Graph (Brabender, Duisburg, Germany) according to the AACC Method 22-10 [17]. The heating and cooling cycles of the instrument were adjusted and maintained at $50^{\circ} \mathrm{C}$ for $1 \mathrm{~min}$ after sample loading, followed by increasing temperature to $95^{\circ} \mathrm{C}$ within $7.5 \mathrm{~min}$. The samples were kept for $5.5 \mathrm{~min}$ at $95{ }^{\circ} \mathrm{C}$ and cooled to $50{ }^{\circ} \mathrm{C}$ in $7.5 \mathrm{~min}$ [20]. The parameters measured for each sample included the average values for peak, final, trough, breakdown, and setback viscosities.

\subsection{Micromorphology of biscuits dough}

The microstructure of biscuit dough was evaluated as described by Ali et al. [20]. Briefly, freeze-dried dough samples were cut transversally into slices with a sharp blade. After dehydration, the specimens were coated with gold in an ion coater up to $300 \AA$ using a smart coater with an ion sputtering device (model JFC-1500, Tokyo, Japan) and energy-dispersive $\mathrm{X}$-ray spectroscopy detector (model EX-54175JMU, JEOL, Tokyo, Japan). The micromorphology was observed with a Scanning Electron Microscope (JSM-6380A, JEOL, Tokyo, Japan) at the Centralized Science Laboratories, University of Karachi, Pakistan.

\subsection{Biscuit preparation}

Functional biscuits were prepared by partially replacing fat $[10,15,20,25$, and 50\% (w/w)] with BGF. The biscuit formulations are presented in Table 1. Biscuit samples were prepared as reported by Ali et al. [20]. Briefly, the dough was prepared by creaming fat and sugar in a dough mixer (Kenwood KM240SI, UK) for 3 min, then egg along with soy lecithin were added to the mixer and further mixed for $5 \mathrm{~min}$. Commercial wheat flour, salt, baking powder, and glucose were homogeneously mixed separately and then added to the mixture and mixed along with water for $3 \mathrm{~min}$ to obtain the biscuit dough. The dough was sheeted at a uniform thickness of $7.2 \mathrm{~mm}$ and cut into circular shapes using a biscuit cutter having a fixed diameter of $36.3 \mathrm{~mm}$. About 25 biscuits were made per batch, and each batch was formulated in triplicate.
Table 1 Formulation of biscuits samples

\begin{tabular}{lllllll}
\hline Ingredients (g/100 g) & \multicolumn{7}{l}{ Level of fat replacement } \\
\cline { 2 - 7 } & Control & $10 \%$ BGF & $15 \%$ BGF & $20 \%$ BGF & $25 \%$ BGF & $50 \%$ BGF \\
\hline All-purpose wheat flour (g) & 100 & 100 & 100 & 100 & 100 & 100 \\
Fat/shortening (g) & 40 & 36 & 34 & 32 & 30 & 20 \\
Icing sugar(g) & 40 & 40 & 40 & 40 & 40 & 40 \\
Baking powder (g) & 2 & 2 & 2 & 2 & 2 & 2 \\
Egg (g) & 13.4 & 13.4 & 13.4 & 13.4 & 13.4 & 13.4 \\
Soya lecithin (g) & 0.25 & 0.25 & 0.25 & 0.25 & 0.25 & 0.25 \\
Salt (g) & 1 & 1 & 1 & 1 & 1 & 1 \\
Glucose (g) & 0.5 & 0.5 & 0.5 & 0.5 & 0.5 & 0.5 \\
Distilled water (mL) & 18 & 22 & 24 & 26 & 28 & 36 \\
BGF (g) & - & 04 & 06 & 08 & 10 & 20
\end{tabular}




\subsection{Antioxidant activity and phytochemicals}

For antioxidant activity, control (WF and its biscuits), BGFWF blends, and BGF-WF biscuits were dissolved in methanol at concentrations $60,125,185$, and $250 \mathrm{mg} \mathrm{mL}^{-1}$. Samples were vortexed for $2 \mathrm{~min}$ and sonicated in an Ultrasonicator (SONOREX RK 31, Bandelin Electronic KG, Berlin, Germany) for $30 \mathrm{~min}$. The homogenates were centrifuged at $1500 \times g$ for $5 \mathrm{~min}$, and the final extracts were collected in the form of supernatant [21].

\subsubsection{Free radical scavenging activity by 2 , 2-Diphenyl-1-picryl-hydrazyl}

The technique mentioned by Fan et al. [22] with slight modification was used to determine the antioxidant activity of control, BGF-WF blends and BGF-WF biscuits. Briefly, 2, 2-diphenyl-1-picrylhydrazyl (DPPH) solution was prepared by dissolving $33.9 \mathrm{mg}$ DPPH in $100 \mathrm{~mL}$ of methanol. Previously prepared samples $(1 \mathrm{~g})$ were mixed with $\mathrm{DPHH}(1 \mathrm{~mL})$ and kept in the dark for $30 \mathrm{~min}$. Absorbance (Abs) values were estimated at the wavelength of $517 \mathrm{~nm}$ using a spectrophotometer (Perkin Elmer, Lambda 25, and UV-Vis Spectrophotometer). The $I C_{50}$ value $(\mathrm{mg} / \mathrm{mL})$ of samples was obtained by interpolation from the linear regression analysis.

The scavenging activity was determined as follows.

Scavenging activity $\%=($ Abs of control-Abs of sample $)$

/Abs of control $\times 100$

\subsubsection{Ferric/Ferricyanide (Fe3+) reducing antioxidant power}

Ferric/Ferricyanide (Fe3+) reducing antioxidant power (FRAP) was analyzed by the method of Oyaizu [23], with slight modification, as adapted by Gawlik et al. [24]. The Perl's Prussian color formation was measured at an Abs of $700 \mathrm{~nm}$ using a spectrophotometer (Perkin Elmer, Lambda 25, and UV-Vis Spectrophotometer). An increase in Abs value demonstrated increased antioxidant activity. $I C_{50}$ values $(\mathrm{mg} / \mathrm{mL})$ of samples were also determined.

\subsubsection{Total phenolic content}

Total phenolic content (TPC) of BGF-WF blends and BGFWF biscuits were determined using Folin-Ciocalteu reagent, as described by Salar and Purewal, [25]. The Abs of the extracts was recorded at $765 \mathrm{~nm}$ by using a spectrophotometer (Perkin Elmer, Lambda 25, and UV-Vis Spectrophotometer) against blank, and results were expressed as milligram Gallic acid equivalent/100 g (mg GAE/100 g) of the extract on dry weight (dw) basis obtained from the standard calibration curve.

\subsubsection{Total flavonoid content}

Total Flavonoid Content (TFC) of BGF-WF and BGF-WF biscuits were determined by the method of Dewanto et al. [26]. The Abs of the extracts at $510 \mathrm{~nm}$ was measured by utilizing a spectrophotometer (Perkin Elmer, Lambda 25, and UV-Vis Spectrophotometer). Catechin was used as a standard, and results were expressed as $\mathrm{mg}$ Catechin equivalent/100 $\mathrm{g}(\mathrm{mg} \mathrm{CE} / 100 \mathrm{~g})$ of the extract, on dw basis.

\subsection{Evaluation of quality attributes of biscuits}

\subsubsection{Dimensional and textural analysis of biscuits}

Dimensional measurements (product diameter, thickness, and spread ratio) of biscuits were determined according to AACC Method 10-50D [17], in order to compare the fatreplaced biscuits with control product. The diameter of biscuits was measured using a Vernier caliper (by rotating the biscuit twice by $90^{\circ}$ ). The thickness of biscuits was measured by stacking six biscuits on top of one another; this total-height measurement was divided by six to get the average value. The spread ratio of biscuits was calculated from the ratio of diameter over thickness. Each of these measurements was performed in triplicate.

Hardness, in terms of the breaking strength of a biscuit, was measured using a TA.XT+ Texture Analyzer (TA. TX2, Stable Micro Systems Ltd., UK), according to a threepoint bend rig and technique (load cell: $5 \mathrm{~kg}$, pre-test speed: $1.0 \mathrm{~mm} / \mathrm{s}$, test speed: $5.0 \mathrm{~mm} / \mathrm{s}$, post-test speed: $10.0 \mathrm{~mm} / \mathrm{s}$, distance: $10 \mathrm{~mm}$, trigger force: $50 \mathrm{~g}$ ). Biscuits from each individual batch were used for textural analysis.

\subsubsection{Color analysis}

Biscuit color was measured using an NH300 Portable Colorimeter, China according to the method of Ohizua et al. [27]. Color values for $L^{*}, a^{*}$, and $b^{*}$ were recorded. Each value represented the average of four measurements at different points on the surface of a biscuit. The $L^{*}$ value is the lightness variable, from 100 for perfect white to zero for black, while the* and $b^{*}$ values are the chromaticity values that indicate $(+)$ redness/ $(-)$ greenness and $(+)$ yellowness/ (-) blueness, respectively.

\subsubsection{Nutritional analysis}

Protein content (AACC Method 08-01) and ash content (AACC Method 46-10) were analyzed using a Kjeldahl apparatus (Thermo Fisher Scientific, 3434, US) and a Muffle 
furnace (Thermo Fisher Scientific, 50056360, USA), respectively [17]. Fat content (AACC Method 30-25) and crude fiber content (AACC Method 32-10) were determined using a Soxhlet extractor (Thermo Fisher Scientific, USA) and a fiber digester (Marconi, MA-444, Brazil), respectively [17]. Moisture content was estimated using a moisture analyzer (Brabender 51-55, CW Brabender, Duisbury, NJ, USA). Total carbohydrate was estimated by difference: carbohydrate $=100-(\%$ moisture $+\%$ protein $+\%$ fat $+\%$ ash $+\%$ crude fiber). Calories were calculated by applying the Atwater general factor system: carbohydrate $(4 \mathrm{kcal} / \mathrm{g})$, lipid $(9 \mathrm{kcal} / \mathrm{g})$, and protein $(4 \mathrm{kcal} / \mathrm{g})$.

\subsubsection{Sensorial evaluation}

Sensory analysis was carried out in our baking laboratory, following the methodology of Ali et al. [20]. Biscuit samples were evaluated by 40 trained panelists, male and female (ages 24-45), comprised mainly of students and staff members of the Department of Food Science and Technology, University of Karachi (Karachi, Pakistan). The panelists were trained by utilizing the sensory profiles method Lawless \& Heymann [28] with the commercial biscuits and prototypes prepared in the baking laboratory. By means of this training, a specific terminology for the sensory characteristics and ranges for each attribute was agreed upon. The characterization of the products was carried out under daylight and in portable cabins within the sensory laboratory. Panelists used a 9-point hedonic scale (1: extremely dislike to 9: extremely like) for analyzing biscuit samples for taste, color, appearance, texture, and overall acceptability. Samples of biscuits were randomly selected, labeled with 3-digit numbers, and then presented on white plastic plates, in random order, to the panelists.

\subsection{Statistical analysis}

All analyses were performed in triplicate, and the average values were calculated. The results were expressed as mean \pm standard deviation (SD). The data were evaluated by analysis of variance (ANOVA), using the SPSS software (Version 17.0, Chicago, USA) statistical program. Duncan's multiple range tests were applied to identify any significant differences among the treatments, at a 95\% confidence level $(P \leq 0.05)$. Principal component analysis (PCA) of experimental data was used to reduce the number of variables in the data, by extracting the important ones from a large pool, using XLSTAT software (Addinsoft 2020, version 2019.2.1, Paris, France). PCA was separately applied to the proximate, rheological, functional, antioxidant, and phytochemical characteristics of the flour blends.

\section{Results and discussion}

\subsection{Proximate composition of flour blends}

Proximate profile of flour blends is represented in Table 2. The moisture content in flour samples varied from 13.30 to $14.10 \%$ with $100 \%$ WF (control) having the highest value. The lower values of BGF-WF blends is advantageous because it will reduce the proliferation of spoilage organisms, especially mold, thus, improving the shelf stability of the product [29]. The highest protein content (18.72\%) was found for the $50 \%$ BGF sample, and the lowest (9.81\%) for the commercial wheat flour (control). The ash contents were in the range from 0.43 to $2.21 \%$. Refined wheat flour contained a significantly $(P \leq 0.05)$ higher amount of total gluten content (both dry and wet). The lowest total gluten content was estimated at 25\% BGF and 50\% BGF. Ali et al. [20] reported similar results by incorporating black gram flour into wheat flour, which resulted in increased moisture, ash, and protein ratio. Increased moisture content

Table 2 Effect of Black gram flour (BGF) addition on proximate and chemical properties of blends with wheat flour

\begin{tabular}{|c|c|c|c|c|c|c|c|}
\hline \multirow[t]{2}{*}{ Sample } & \multirow[t]{2}{*}{ Moisture content (\%) } & \multirow[t]{2}{*}{ Ash (\%) } & \multirow[t]{2}{*}{ Protein (\%) } & \multicolumn{4}{|l|}{ Gluten } \\
\hline & & & & Dry (\%) & Wet (\%) & Gluten index & Total gluten content $\%$ \\
\hline Wheat flour (control) & $14.10 \pm 0.12^{d}$ & $0.43 \pm 0.01^{\mathrm{a}}$ & $9.81 \pm 0.10^{\mathrm{a}}$ & $9.20 \pm 0.2^{\mathrm{cd}}$ & $25.80 \pm 0.26^{c}$ & $95.00 \pm 1.20^{f}$ & $35.0 \pm 0.31^{d}$ \\
\hline $10 \%$ BGF & $13.32 \pm 0.14^{b}$ & $0.73 \pm 0.03^{b}$ & $15.70 \pm 0.12^{b}$ & $9.20 \pm 0.14^{\mathrm{cd}}$ & $24.80 \pm 0.20^{c}$ & $93.00 \pm 1.01^{e}$ & $34.0 \pm 0.13^{c}$ \\
\hline $15 \%$ BGF & $13.33 \pm 0.10^{b}$ & $0.73 \pm 0.01^{b}$ & $15.91 \pm 0.11^{c}$ & $9.10 \pm 0.10^{c}$ & $24.90 \pm 0.11^{d}$ & $90.00 \pm 1.17^{d}$ & $34.0 \pm 0.21^{c}$ \\
\hline $20 \%$ BGF & $13.71 \pm 0.11^{c}$ & $1.86 \pm 0.02^{c}$ & $17.11 \pm 0.15^{c}$ & $9.00 \pm 0.21^{c}$ & $25.00 \pm 0.21^{d}$ & $88.00 \pm 1.10^{c}$ & $34.0 \pm 0.40^{c}$ \\
\hline $25 \%$ BGF & $13.82 \pm 0.12^{c}$ & $1.87 \pm 0.06^{c}$ & $17.42 \pm 0.20^{d}$ & $8.70 \pm 0.10^{b}$ & $14.60 \pm 0.13^{b}$ & $85.00 \pm 1.11^{b}$ & $23.3 \pm 0.20^{b}$ \\
\hline $50 \%$ BGF & $13.81 \pm 0.13^{c}$ & $3.21 \pm 0.08^{d}$ & $20.10 \pm 0.22^{\mathrm{e}}$ & $8.30 \pm 0.11^{\mathrm{a}}$ & $11.80 \pm 0.17^{\mathrm{a}}$ & $78.00 \pm 0.90^{\mathrm{a}}$ & $20.1 \pm 0.16^{a}$ \\
\hline BGF & $9.10 \pm 0.01^{\mathrm{a}}$ & $5.43 \pm 0.09^{e}$ & $27.20 \pm 0.25^{f}$ & - & - & - & - \\
\hline
\end{tabular}

$a, b, c, d, e, f$ Mean followed by different letters in the same column differs significantly $(P \leq 0.05)$. Calculations were made using Duncan method. Each value expressed as mean $\pm S D(n=3)$ 
(Table 2) and water absorption (Table 3) also attributed that protein in BGF has a remarkable effect on water holding capacity [20]. Lower gluten contents in BGF-WF blends may indicate the interference of seed coat components of BGF in gluten network development, as reported earlier [20], which was also confirmed by micrograph scanning image (Fig. 2). Another obvious, reason is that the storage proteins in BGF are not of the gluten type characteristic of those in cereal grains such as wheat [20]. The above findings were in agreement with those reported previously by Ali et al. [20].

\subsection{Functional properties of flour blends}

\subsubsection{Swelling power}

Klunklin and Savage [30] defined swelling power (SP) as the concentration of starch granules in flour, which can retain water. The SP values shown in Table 3 for the BGF-WF blends increased with the increasing proportion of BGF in the flour blends and ranged from 4.76 to $6.21 \mathrm{~g} \mathrm{~g}^{-1}$. This trend of increasing SP was similar to that reported by Klunklin and Savage [30]. The results depicted

Table 3 Effect of different levels of added Black gram flour (BGF) on functional properties of blends with wheat flour

\begin{tabular}{llllll}
\hline Sample & Swelling power $\left(\mathrm{g} \mathrm{g}^{-1}\right)$ & $\begin{array}{l}\text { Water absorp- } \\
\text { tion capacity } \\
(\%)\end{array}$ & Oil binding capacity (\%) & Emulsion capacity (\%) & Emulsion stability (\%) \\
\hline Wheat flour (control) & $4.76 \pm 0.02^{\mathrm{b}}$ & $145.60 \pm 1.01^{\mathrm{a}}$ & $153.17 \pm 2.10^{\mathrm{g}}$ & $44.10 \pm 0.5^{\mathrm{g}}$ & $37.01 \pm 0.05^{\mathrm{a}}$ \\
$10 \%$ BGF & $4.69 \pm 0.02^{\mathrm{a}}$ & $146.96 \pm 1.01^{\mathrm{b}}$ & $150.21 \pm 2.11^{\mathrm{f}}$ & $45.06 \pm 0.3^{\mathrm{f}}$ & $48.01 \pm 0.12^{\mathrm{b}}$ \\
$15 \%$ BGF & $4.89 \pm 0.05^{\mathrm{c}}$ & $148.6 \pm 1.05^{\mathrm{c}}$ & $149.71 \pm 1.07^{\mathrm{e}}$ & $47.13 \pm 0.3^{\mathrm{e}}$ & $56.03 \pm 0.07^{\mathrm{c}}$ \\
$20 \%$ BGF & $5.27 \pm 0.04^{\mathrm{d}}$ & $150.26 \pm 2.03^{\mathrm{d}}$ & $146.82 \pm 2.01^{\mathrm{d}}$ & $50.86 \pm 0.4^{\mathrm{d}}$ & $69.27 \pm 0.11^{\mathrm{d}}$ \\
$25 \%$ BGF & $5.86 \pm 0.01^{\mathrm{e}}$ & $155.40 \pm 1.04^{\mathrm{e}}$ & $140.30 \pm 1.00^{\mathrm{c}}$ & $57.71 \pm 0.2^{\mathrm{c}}$ & $75.77 \pm 0.1^{\mathrm{e}}$ \\
$50 \%$ BGF & $6.27 \pm 0.08^{\mathrm{f}}$ & $162.24 \pm 1.08^{\mathrm{f}}$ & $128.46 \pm 1.11^{\mathrm{b}}$ & $66.21 \pm 0.5^{\mathrm{b}}$ & $83.19 \pm 0.14^{\mathrm{f}}$ \\
BGF & $7.09 \pm 0.06^{\mathrm{g}}$ & $200.31 \pm 1.02^{\mathrm{g}}$ & $75.22 \pm 1.03^{\mathrm{a}}$ & $71.42 \pm 0.6^{\mathrm{a}}$ & $89.66 \pm 0.16^{\mathrm{g}}$ \\
\hline
\end{tabular}

$a, b, c, d, e, f, g$ Mean followed by different letters in the same column differs significantly $(P \leq 0.05)$. Calculations were made using Duncan method. Each value expressed as mean $\pm S D(n=3)$
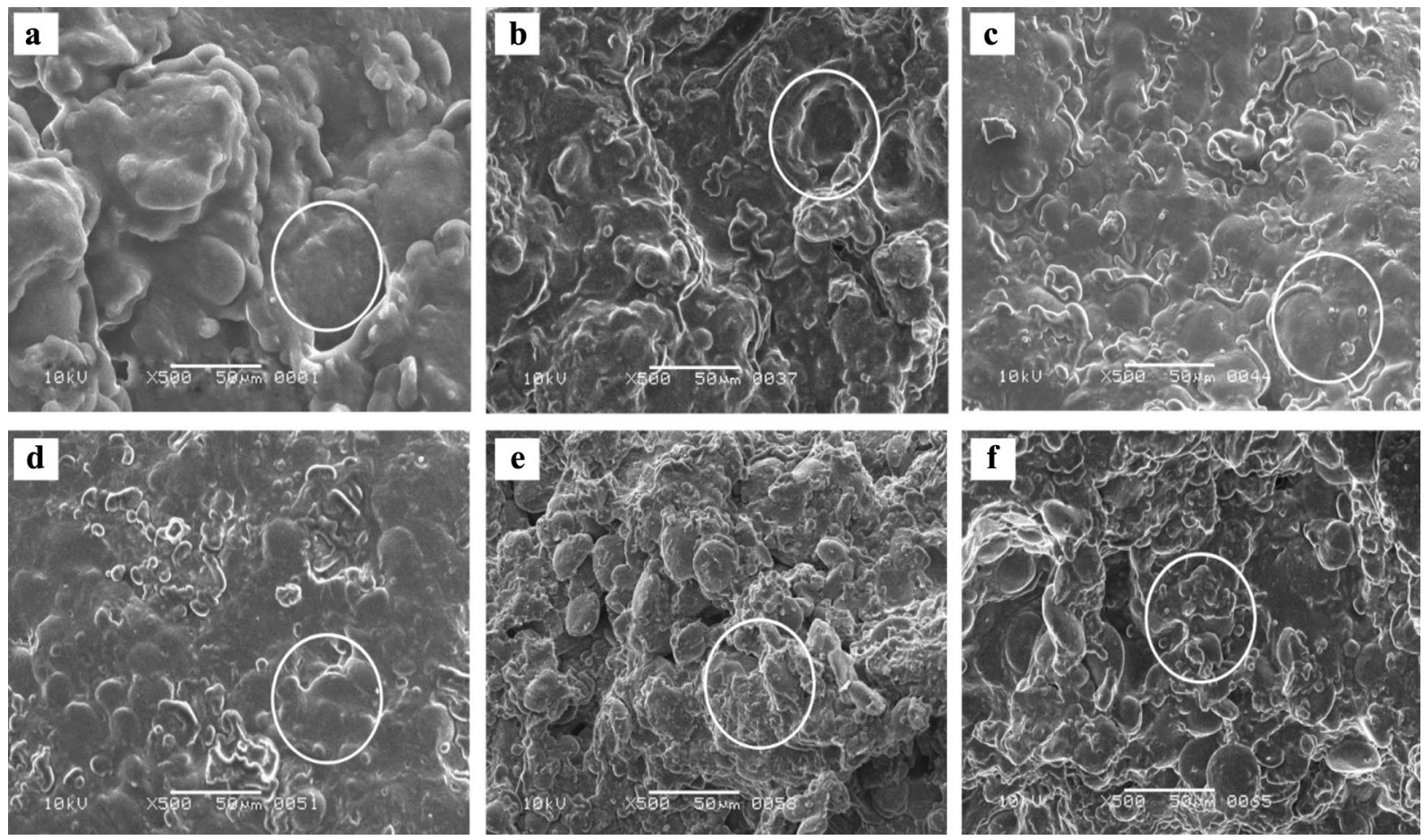

Fig. 2 Scanning electron micrograph of biscuit's dough at $500 \times$ (a) Dough without fat replacement-Control (b) Dough with Black gram flour (BGF) $10 \%$ (c) BGF 15\%, (d) BGF 20\%, (e) BGF 25\% and (f) BGF 50\% 
that swelling of flour blends increases due to high level of amylopectin in BGF. Hence, we suggest that such BGFWF blends can increase the viscosity of a food system and thereby act as carbohydrate-based fat mimetics, which typically perform a fat replacement role by holding water in the food product in a gel-like matrix. This results in increased viscosity and body and a creamy mouthfeel, similar to that of full-fat products [31].

\subsubsection{Water absorption and oil binding capacity}

Water absorption capacity (WAC) and oil binding capacity $(\mathrm{OBC})$ are two critical functional properties of an ingredient determining the texture, mouthfeel, and yield of the final product [32]. The water absorption capacity of flour blends ranged from 146.96 to $162.24 \%$ (Table 3 ). The highest WAC was observed for 50\% BGF (162.24\%), followed by BGF $25 \%$ (155.40\%), and lowest for $10 \%$ BGF (146.96\%). With the increasing BGF in WF there is a concomitant increase in WAC. Similar results were reported when rice, green gram and potato starch added to WF [32]. The higher WAC might be due to the difference in fiber and carbohydrate contents of BGF, which facilitate water absorption due to the presence of large numbers of hydroxyl groups [33]. The improved WAC of our blends suggests that the addition of BGF to bakery products is desirable and meets the demands of increased water content in products [34].

The OBC of wheat flour reduced from 153 to $129 \%$ by adding BGF in our blends (Table 3 ). Similarly, Klunklin and Savage [22] showed a decrease in OBC by increasing levels of purple rice in wheat flour. Protein in flour contains both hydrophobic and hydrophilic parts, which are responsible for oil and water absorption capacity [35]. Results suggest that BGF proteins are more likely to be hydrophilic as the incorporation of BGF decreased the OBC. Plant food polysaccharides, including fibers and carbohydrates, are typically good fat replacers due to their ability to bind water to form a paste which can mimic the texture and viscosity of fats in food products by providing lubrication or flow properties similar to fat [31]. Lubrication and moisture retention are two desirable attributes of bakery fat, which are required in various dough formulations [36]. The increased WACs of the BGF-WF blends illustrated their manifestation of these characteristics of bakery fat.

\subsubsection{Emulsion capacity and emulsion stability}

Emulsion capacity (EC) of BGF-WF blends ranged from 45.06 to $66.21 \%$. Blend containing 50\% BGF showed the highest EC (66.21\%), followed by 25\% BGF (57.71\%), while the lowest EC was observed for 10\% BGF (45.06\%). Besides, emulsion stability (ES) for BGF-WF blends varied from 48.01 to $83.19 \%$ (Table 3). Highest ES was observed for $50 \%$ BGF (783.19\%) followed by $25 \%$ BGF $(75.77 \%)$ and lowest for $10 \%$ BGF (48.01\%). EC and ES are the two indices often used to assess the emulsifying properties of the protein. Emulsifying properties of proteins are affected by their hydrophobicity/ hydrophilicity ratio [31]. The increase in the amount of BGF in wheat flour showed a significant $(P \leq 0.05)$ increase in $\mathrm{EC}$ and $\mathrm{ES}$. Moreover, a significant $(P \leq 0.05)$ reduction in ES was observed for WF; the decrease might be responsible due to coalescence when numerous small molecules of oil combine to form large molecules and ultimately results in emulsion breakage [30]. The high ES of BGF-WF blends could be due to the formation of highly cohesive films by the absorption of rigid globular protein molecules that are progressively resistant to mechanical damage [30]. Another reason could be the increase in viscosity, which restricts the phenomena of coalescence by restricting the movement of molecules within the system [30]. Hence results from our study suggested that BGF proteins contain significant proportions of both hydrophobic and hydrophilic components of amino acids required for the development of emulsion. Thus, such BGF-WF blends may be capable of acting as excellent emulsion stabilizers and emulsifiers, both attributes of which can be essential for the replacement of typical bakery fat in various baked products $[31,28]$.

\subsubsection{Solvent retention capacities of BGF-WF blends}

The solvent retention capacity (SRC), as a functional property of wheat flour, is influenced by the rate of flour extraction during milling [37]. A greater extent of flour extraction generally results in increased amounts of damaged starch and bran in the flour, which leads to increased SRC values, especially for sucrose and sodium carbonate [37]. The lactic acid SRC value of flour is dependent on the quality and quantity of glutenin, while the sucrose SRC value is related to the pentosans in the flour [37]. The water SRC value is influenced by the three hydrophilic polymeric components in a flour, i.e., damaged starch, gluten protein, and pentosans [37]. Strong correlations between each of the four SRC values and the three individual functional polymeric components of flour, i.e., gluten protein, damaged starch, and pentosans, have been described by Kweon et al. [37] and demonstrated to be predictive of the functional contribution of each of those flour components to overall flour functionality and end-product quality. As shown by the results in Table 4, as the proportion of BGF in the BGF-WF blends increased, the water, lactic acid, sodium carbonate, and sucrose SRC values all increased significantly $(P \leq 0.05)$, in contrast to related findings previously reported by Portman et al. [38]. According to Portman et al. [38], their sucrose, lactic acid, and 
Table 4 Solvent retention capacity (SRC) of wheat flour and Black gram flour (BGF) containing blends

\begin{tabular}{lcccc}
\hline Sample & Water SRC (\%) & Sucrose SRC (\%) & Lactic acid SRC (\%) & Sodium carbonate SRC (\%) \\
\hline Wheat flour (control) & $55.31 \pm 1.12^{\mathrm{a}}$ & $90.50 \pm 1.10^{\mathrm{a}}$ & $81.33 \pm 1.12^{\mathrm{c}}$ & $64.79 \pm 1.15^{\mathrm{a}}$ \\
$10 \%$ BGF & $64.09 \pm 1.16^{\mathrm{b}}$ & $93.72 \pm 1.16^{\mathrm{b}}$ & $42.16 \pm 1.14^{\mathrm{a}}$ & $76.07 \pm 1.17^{\mathrm{b}}$ \\
$15 \%$ BGF & $76.13 \pm 1.22^{\mathrm{c}}$ & $100.99 \pm 1.17^{\mathrm{c}}$ & $51.12 \pm 1.25^{\mathrm{b}}$ & $104.58 \pm 2.19^{\mathrm{c}}$ \\
$20 \%$ BGF & $98.83 \pm 1.29^{\mathrm{d}}$ & $104.69 \pm 1.25^{\mathrm{d}}$ & $86.29 \pm 2.10^{\mathrm{d}}$ & $112.68 \pm 2.33^{\mathrm{d}}$ \\
$25 \%$ BGF & $100.37 \pm 1.24^{\mathrm{e}}$ & $154.35 \pm 1.2^{\mathrm{e}}$ & $102.95 \pm 2.31^{\mathrm{e}}$ & $129.39 \pm 2.25^{\mathrm{e}}$ \\
$50 \%$ BGF & $171.53 \pm 2.26^{\mathrm{f}}$ & $195.38 \pm 1.26^{\mathrm{f}}$ & $133.36 \pm 2.27^{\mathrm{f}}$ & $200.214 \pm 2.37^{\mathrm{f}}$ \\
BGF & $312.58 \pm 4.10^{\mathrm{g}}$ & $443.31 \pm 3.14^{\mathrm{g}}$ & $263.11 \pm 3.13^{\mathrm{g}}$ & $487.92 \pm 3.65^{\mathrm{g}}$ \\
\hline
\end{tabular}

$a, b, c, d, e, f$ Means followed by different letters in the same column differs significantly $(P \leq 0.05)$. Calculations were made using Duncan method. Each value expressed as mean $\pm S D(n=3)$

sodium carbonate SRC values decreased with an increasing proportion of lentil flour in blends with wheat flour. However, the positive correlations among the SRC values and the BGF-WF blend compositions, seen in the present study, suggested that this BGF flour had levels of damaged starch, pentosans, and storage proteins higher than those of the control wheat flour.

\subsection{Rheological characteristics}

\subsubsection{Dough rheological properties during mixing}

Dough rheology during mixing was analyzed in terms of water absorption (WA), dough development time (DDT), dough stability time (DST), and Farinograph quality number (FQN), as illustrated by the results shown in Table 5 . A significant $(P \leq 0.05)$ increase in WA was observed for increasing proportions of BGF in the BGF-WF blends. Ali et al. [20] reported a similar finding that the WA for wheat flour-black gram flour blends increased with increasing incorporation of black gram flour. However, the amounts of BGF added to WF in the present study were much higher (10 to $50 \% \mathrm{~W} / \mathrm{w})$, and the resulting values of WA were much lower, compared to those reported by Ali et al. [20]. The association of rheological quality with soluble and insoluble dietary fiber contents has been noted by
Issarny et al. [39]. In the present study, the addition of BGF to wheat flour is believed to have disrupted the gluten network to a notable extent, and thereby to have affected the baking quality of the dough. The WA, DDT, and FQN parameters, for the $15 \%$ and $20 \%$ BGF samples did not differ significantly $(P \leq 0.05)$ (Table 5$)$, but DDT increased significantly $(P \leq 0.05)$ for the $25 \%$ and $50 \%$ BGF samples. Turfani et al. [40] reported similar findings, whereby DDT increased with increasing addition of lentil flour to wheat flour. In the present study, the reason for the increased DDT could be related to the relatively higher affinity of BGF than wheat gluten for water. In fact, the wheat flour control showed a much lower DDT than any of the BGF-WF blends. An increase in fiber content, due to the added BGF, might account for the observed differences in the mixing profiles of the flour blends [41]. Another reason could be associated with the much-increased FQN for the $15 \%-50 \%$ BGF-WF blends, which related to a hardening effect in the dough and, ultimately to delays in DDT and DST [20].

\subsubsection{Dough viscometric properties}

The Micro Visco-Amylo-Graph parameters of WF control and BGF-WF blends are presented in Table 6. Higher peak viscosities were observed for the $20 \%$ BGF, $15 \%$ BGF, and $10 \%$ BGF samples, while lower peak viscosities were
Table 5 Farinograph properties of wheat flour and Black gram flour (BGF) incorporated containing blends

\begin{tabular}{llccr}
\hline Sample & Water absorption (\%) & $\begin{array}{l}\text { Dough develop- } \\
\text { ment time (min) }\end{array}$ & $\begin{array}{l}\text { Dough stability } \\
\text { time (min) }\end{array}$ & $\begin{array}{l}\text { Farinograph } \\
\text { quality num- } \\
\text { ber }\end{array}$ \\
\hline Wheat flour (control) & $58.70 \pm 0.2^{\mathrm{a}}$ & $1.67 \pm 0.01^{\mathrm{a}}$ & $8.58 \pm 0.18^{\mathrm{a}}$ & $88.01 \pm 1.12^{\mathrm{b}}$ \\
$10 \%$ BGF & $63.60 \pm 0.20^{\mathrm{b}}$ & $5.92 \pm 0.12^{\mathrm{b}}$ & $8.61 \pm 0.1^{\mathrm{a}}$ & $77.02 \pm 1.09^{\mathrm{a}}$ \\
$15 \%$ BGF & $64.50 \pm 0.33^{\mathrm{c}}$ & $7.81 \pm 0.24^{\mathrm{c}}$ & $8.82 \pm 0.4^{\mathrm{b}}$ & $120.11 \pm 2.24^{\mathrm{c}}$ \\
$20 \%$ BGF & $64.90 \pm 0.51^{\mathrm{c}}$ & $7.80 \pm 0.22^{\mathrm{c}}$ & $9.60 \pm 0.2^{\mathrm{c}}$ & $120.03 \pm 2.01^{\mathrm{c}}$ \\
$25 \%$ BGF & $65.81 \pm 0.58^{\mathrm{d}}$ & $8.11 \pm 0.16^{\mathrm{d}}$ & $10.22 \pm 0.33^{\mathrm{d}}$ & $127.04 \pm 1.04^{\mathrm{d}}$ \\
$50 \%$ BGF & $72.40 \pm 0.81^{\mathrm{e}}$ & $11.50 \pm 0.14^{\mathrm{e}}$ & $13.10 \pm 0.40^{\mathrm{e}}$ & $139.12 \pm 2.02^{\mathrm{e}}$ \\
\hline
\end{tabular}

a, b, c, d, e Means followed by different letters in the same column differs significantly $(P \leq 0.05)$. Calculations were made using the Duncan method. Each value expressed as mean \pm S.D. $(n=3)$ 
observed for the $50 \%$ BGF and $25 \%$ BGF samples. The high peak viscosity observed for some of the flour blends might be associated with swelling power or water absorption capacity of starch molecules. On the other hand, the lower peak viscosities observed have been suggested to be due to increased protein-to-protein, starch-to-starch, and protein-to-starch interactions upon the addition of the higher amounts of BGF [20]. Another reason for decreased viscosity was weaker resistance of wheat with a higher amount of BGF under heating and shear mixing due to an increased level of non-starch substances [41].

Additionally, trough, breakdown, and setback viscosities decreased significantly $(P \leq 0.05)$ as the levels of BGF increased in wheat flour. The decreases in these viscosities have been suggested to reflect a reduced tendency for starch retrogradation, and consequent inhibition of the staling of biscuits [42]. Gomez et al. [43] reported similar results, including observed decreases in breakdown and setback viscosities, when chickpea flour was incorporated into blends with wheat flour. The final viscosity of all flour blends decreased when the concentration of BGF increased. It was reported previously that such decreases in final viscosity might be due to the dis-aggregation of amylose molecules [44], such as with increased levels of BGF in the blends with wheat flour.

\subsection{Scanning electron microscopy (SEM) of biscuit doughs}

Scanning electron micrographs of the interior cross-sectional region of biscuit doughs are shown in Fig. 2. The dough formation results in agglomeration of proteins and starch, partly enclosing fat present in the dough. In these circumstances, dough with a high-fat content (control, $10 \%$ BGF, and 15\% BGF) appeared to show some regions in which the smooth surfaces could be viewed as representing fat surrounding protein-starch aggregates (Fig. 2a-c). However, in the lower-fat-content doughs (20\% BGF, $25 \%$ BGF, and $50 \%$ BGF), those smooth flat surfaces were not visible, while small and large starch granules could be seen (Fig. $2 d-f$ ). Although the limited fat present did serve to lubricate the matrix, the amount was apparently not enough to form a continuous coating layer over the surfaces of these samples. Rodriguez et al. [3] reported similar findings when inulin was used as a fat replacer in a cake. The control biscuit dough (Fig. 2a) showed a continuously smooth surface, within which the matrix of associated wheat starch and gluten apparently developed uniformly. In the $25 \%$ BGF and 50\% BGF biscuit doughs, an arrangement of small fragments of developed gluten network appears to have formed (Fig. 2e, f), which may have resulted from a lack of hydration of gluten and the wheat endosperm fragments [45]. Furthermore, the gluten matrix present appeared to be discontinuous, evidently because of the higher levels of fat replacement by BGF, which resulted in the starch granules being leached out of the network and made prominently identifiable (Fig. 2e, f). Uniform sized wheat starch granules were observed in control WF dough, whereas both small and large granules from both BGF and WF were observed in doughs containing 25\% BGF and 50\% BGF (Fig. 2e, f). Similar results were reported by Madhumitha and Prabhasankar [46] utilization $30 \%$ BGF as a fat substitute in the formulation of pasta dough.

Moreover, starch granules appeared to be coated in a protein matrix in doughs containing $15 \%$ and $20 \%$ BGF (Fig. 2c, d). This finding was in agreement with the results of Dachana et al. [47], in which dried moringa leaves powder was incorporated into cookie doughs. The literature revealed that even though microstructural properties of fat replacers are quite different from fat when they are utilized in food products, although the end products do show comparable qualities to the standard formulation, which was also confirmed from our observations [42].

Table 6 Micro Visco-Amylo-Graph properties of wheat flour and Black gram flour (BGF) containing blend

\begin{tabular}{|c|c|c|c|c|c|c|c|}
\hline Sample & $\begin{array}{l}\text { Peak viscosity } \\
\text { (cP) }\end{array}$ & $\begin{array}{l}\text { Trough viscos- } \\
\text { ity }(\mathrm{cP})\end{array}$ & $\begin{array}{l}\text { Final viscosity } \\
\text { (cP) }\end{array}$ & $\begin{array}{l}\text { Setback viscos- } \\
\text { ity (cP) }\end{array}$ & Breakdown (cP) & Peak time (min) & $\begin{array}{l}\text { Pasting tem- } \\
\text { perature }\left({ }^{\circ} \mathrm{C}\right)\end{array}$ \\
\hline $\begin{array}{l}\text { Wheat flour } \\
\text { (control) }\end{array}$ & $2074 \pm 10.01^{a}$ & $1434 \pm 4.45^{a}$ & $3084 \pm 18.00^{f}$ & $958 \pm 6.10^{e}$ & $7561 \pm 4.11^{\mathrm{a}}$ & $4.30 \pm 0.20^{\mathrm{a}}$ & $57.12 \pm 0.23^{a}$ \\
\hline $10 \% \mathrm{BGF}$ & $2872 \pm 14.00^{d}$ & $2224 \pm 11.00^{b}$ & $2788 \pm 16.05^{\mathrm{e}}$ & $1052 \pm 7.40^{f}$ & $1142 \pm 8.30^{f}$ & $6.11 \pm 0.21^{d}$ & $76.10 \pm 0.3^{d}$ \\
\hline $15 \%$ BGF & $2884 \pm 15.00^{e}$ & $2624 \pm 12.03^{d}$ & $2764 \pm 16.00^{d}$ & $932 \pm 5.30^{d}$ & $924 \pm 7.51^{\mathrm{e}}$ & $7.20 \pm 0.40^{e}$ & $81.01 \pm 0.34^{e}$ \\
\hline $20 \%$ BGF & $2910 \pm 18.02^{f}$ & $2700 \pm 13.11^{f}$ & $2500 \pm 13.02^{c}$ & $642 \pm 5.10^{b}$ & $910 \pm 7.22^{d}$ & $7.30 \pm 0.20^{\mathrm{e}}$ & $81.02 \pm 0.15^{\mathrm{e}}$ \\
\hline $25 \%$ BGF & $2860 \pm 12.01^{c}$ & $2694 \pm 14.00^{\mathrm{e}}$ & $2260 \pm 12.11^{b}$ & $314 \pm 3.20^{c}$ & $902 \pm 6.40^{c}$ & $5.32 \pm 0.40^{c}$ & $72.11 \pm 0.17^{c}$ \\
\hline $50 \%$ BGF & $2836 \pm 12.00^{b}$ & $2362 \pm 10.01^{c}$ & $2118 \pm 11.01^{\mathrm{a}}$ & $162 \pm 2.20^{\mathrm{a}}$ & $894 \pm 5.13^{b}$ & $4.82 \pm 0.10^{b}$ & $68.14 \pm 0.21^{b}$ \\
\hline
\end{tabular}

$a, b, c, d$, ef Mean followed by different letters in the same column differ significantly $(P \leq 0.05)$. Calculations were made using the Duncan method. Each value expressed as mean \pm S.D. $(n=3)$ 


\subsection{Antioxidant activities and polyphenolics of flour blends and resulting biscuits}

Table 7 shows results for 2,2-diphenyl-1-picryl-hydrazyl (DPPH) radical scavenging activity and ferric/ferricyanide $\left(\mathrm{Fe}^{3+}\right)$ reducing antioxidant power (FRAP), in the form of $\mathrm{IC}_{50}$ values, for the BGF-WF flour blends and BGF-WF resulting biscuits. Increasing the level of BGF in the blends with WF increased the DPPH radical scavenging activities of the BGF-WF blends and BGF-WF biscuits, as evidenced by the decreasing $\mathrm{IC}_{50}$ values shown in Table 7. The WF control samples showed the highest $I C_{50}$ values, which correlated with their lowest DPPH radical scavenging activities. The increased radical scavenging activities of the BGF-WF blends and BGF-WF biscuits signify the increasing presence of radical scavengers or inhibitors provided by the BGF, thus suggesting BGF's probable role as a primary antioxidant. Moreover, biscuit baking appeared to further improve DPPH radical scavenging activity, possibly because of the development of melanoidins during baking [48]. Such melanoidins (brown-color pigments) have been found to be responsible for antioxidant activity [49]. A similar result of an increase in DPPH radical scavenging activity upon baking was also reported by Jan et al. [50] for wheat-based biscuit prepared by incorporating buckwheat flour.

The control WF and its biscuits manifested the lowest FRAPs. The increasingly higher levels of fat replacement in the sample biscuits correlated with increasingly strong reducing powers. Like for the DPPH test results, baking appeared to further improve FRAP, as increasingly lower $\mathrm{IC}_{50}$ values were observed for the BGF-WF biscuits, compared to the BGF-WF flour blends. Similar results, of increases in DPPH radical scavenging activity and FRAP upon baking, were also reported by Jan et al. [50] for WFbased cookies prepared with added buckwheat flour.

Pulses such as BG beans are known to be valuable sources of fiber and protein [51]. They also contain a wide range of polyphenolic compounds, mainly including phenolic acids, flavonoids, and proanthocyanidins [51]. Such compounds play a protecting role in human health through their antioxidant, antiradical, and antiinflammatory attributes [52]. Biscuits prepared from $50 \%$ BGF showed the highest total phenolic content (TPC), followed by the 25\% BGF and 20\% BGF biscuits. Despite the significant decreases $(P \leq 0.05)$ in the TPCs of the BGF -WF biscuits as a consequence of baking, compared to those for the BGF-WF flour blends (Table 7), the TPC values for the BGF-WF biscuits were still higher than that for the control biscuits. The largest decrease in TPC was observed for biscuits containing $10 \%$ BGF, which showed a $36.6 \%$ loss of TPC upon baking, while the smallest decrease was observed for the blend containing 50\% BGF, which showed a 13.2\% loss of TPC upon baking. Jan et al. [50] also found a decrease in the TPC of buckwheat flour after heating at $180^{\circ} \mathrm{C}$. It has been suggested that such reductions in TPC values might be due to alterations in the chemical structures of the phenolic compounds, possible polymerization leading to reduced extractability and oxidation [48].

Phenolic and flavonoid compounds inhibit the formation of free radicals, thus diminishing the rate of oxidation by hindering the development, or by deactivating the

Table 7 Values for 2,2-Diphenyl-1-picryl-hydrazyl (DPPH) radical scavenging activity, total phenolic content (TPC), and total flavonoid content (TFC), for different levels of Black gram flour (BGF) incorporated into wheat flour and resulting biscuit samples

\begin{tabular}{|c|c|c|c|c|c|c|c|c|}
\hline \multirow[t]{2}{*}{ Samples } & \multicolumn{4}{|l|}{ Flour blend } & \multicolumn{4}{|l|}{ Biscuits } \\
\hline & $\begin{array}{l}\mathrm{DPPH}\left(\mathrm{IC}_{50}\right. \\
\mathrm{mg} / \mathrm{mL})\end{array}$ & $\begin{array}{l}\mathrm{FRAP}\left(\mathrm{IC}_{50}\right. \\
\mathrm{mg} / \mathrm{mL})\end{array}$ & $\begin{array}{l}\mathrm{TPC}(\mathrm{mg} \\
\mathrm{GAE}^{1} / 100 \mathrm{~g} \\
\left.\mathrm{DW}^{3}\right)\end{array}$ & $\begin{array}{l}\mathrm{TFC}(\mathrm{mg} \\
\left.\mathrm{CE}^{2} / 100 \mathrm{~g} \mathrm{DW}\right)\end{array}$ & $\begin{array}{l}\mathrm{DPPH}\left(I C_{50}\right. \\
\mathrm{mg} / \mathrm{mL})\end{array}$ & $\begin{array}{l}\operatorname{FRAP}\left(I C_{50}\right. \\
\mathrm{mg} / \mathrm{mL})\end{array}$ & $\begin{array}{l}\text { TPC }(\mathrm{mg} \\
\text { GAE1/100 g } \\
\left.\mathrm{DW}^{3}\right)\end{array}$ & $\begin{array}{l}\mathrm{TFC}(\mathrm{mg} \\
\left.\mathrm{CE}^{2} / 100 \mathrm{~g} \mathrm{DW}^{3}\right)\end{array}$ \\
\hline Control* & $488.01 \pm 3.15^{\mathrm{g}}$ & $327.12 \pm 4.52^{\mathrm{g}}$ & $16.73 \pm 0.11^{a}$ & $18.56 \pm 1.01^{\mathrm{a}}$ & $500.11 \pm 3.15^{p}$ & $350.30 \pm 4.52^{\circ}$ & $14.430 \pm 0.12^{\mathrm{a}}$ & $31.16 \pm 1.01^{\mathrm{a}}$ \\
\hline $10 \%$ BGF & $301.40 \pm 1.29^{f}$ & $127.35 \pm 0.51^{f}$ & $51.64 \pm 1.18^{b}$ & $104.88 \pm 2.21^{b}$ & $255.40 \pm 1.29^{\prime}$ & $114.45 \pm 0.4^{1}$ & $32.74 \pm 2.18^{b}$ & $124.82 \pm 2.81^{b}$ \\
\hline $15 \%$ BGF & $245.62 \pm 1.21^{\mathrm{e}}$ & $121.34 \pm 0.21^{\mathrm{e}}$ & $67.81 \pm 2.31^{c}$ & $319.70 \pm 2.74^{c}$ & $225.62 \pm 1.21^{g}$ & $89.64 \pm 0.3^{j}$ & $49.21 \pm 2.21^{c}$ & $385.30 \pm 2.14^{c}$ \\
\hline $20 \%$ BGF & $221.04 \pm 1.01^{d}$ & $89.32 \pm 0.45^{d}$ & $96.69 \pm 3.42^{d}$ & $344.80 \pm 3.45^{d}$ & $201.04 \pm 1.01^{\mathrm{e}}$ & $75.39 \pm 0.15^{\mathrm{g}}$ & $75.49 \pm 3.12^{d}$ & $426.83 \pm 4.45^{d}$ \\
\hline $25 \%$ BGF & $200.60 \pm 0.92^{c}$ & $78.81 \pm 0.13^{c}$ & $123.37 \pm 3.55^{\mathrm{e}}$ & $373.97 \pm 4.51^{\mathrm{e}}$ & $190.60 \pm 0.92^{d}$ & $69.88 \pm 0.13^{d}$ & $99.34 \pm 3.15^{\mathrm{e}}$ & $468.67 \pm 4.61^{\mathrm{e}}$ \\
\hline $50 \%$ BGF & $187.21 \pm 0.43^{b}$ & $57.62 \pm 0.11^{b}$ & $167.16 \pm 3.81^{f}$ & $421.60 \pm 4.82^{f}$ & $169.21 \pm 0.43^{a}$ & $34.12 \pm 0.12^{\mathrm{a}}$ & $145.13 \pm 3.21^{f}$ & $543.65 \pm 4.72^{f}$ \\
\hline BGF & $62.31 \pm 0.21^{a}$ & $15.31 \pm 0.10^{\mathrm{a}}$ & $421.55 \pm 4.37^{g}$ & $863.71 \pm 5.45^{g}$ & & & & \\
\hline
\end{tabular}

$a, b, c, d, e, f, g$ Mean followed by different letters in the same column differs significantly $(P \leq 0.05)$. Calculations were made using the Duncan method. Each value is expressed as mean $\pm S D(n=3)$

${ }^{1} \mathrm{GAE}=$ gallic acid equivalent

${ }^{2} \mathrm{CE}=$ catechin equivalent

${ }^{3} \mathrm{DW}=$ dry weight of sample

${ }^{*}$ Control represents the control wheat flour and its resulting biscuits 
active species and precursors, of free radicals [53]. Table 5 shows the total flavonoid content (TFC) values for the flour blends and resulting biscuits. TFCs of the biscuits increased with the increasing extent of fat replacement. Biscuits prepared from $50 \%$ BGF showed the highest TFC, while the lowest TFC was observed for the control biscuits. Baking resulted in significant increases $(P \leq 0.05)$ in the TFCs of the BGF-WF biscuits, compared to those for the BGF-WF blends. The largest increment in TPC was observed for biscuits prepared from $50 \% \mathrm{BGF}$, which showed a $22.5 \%$ increment in TFC upon baking, while the smallest increment was observed for the blend containing 10\% BGF, which showed a $16.0 \%$ increase upon baking. The observed differences could be due to the earlier-mentioned development of melanoidins, the brown-colored products of the Maillard reaction that occurs during the baking process [54]. These results also illustrated the positive correlations between TPC and TFC in plant-based foods, as previously reported by Oboh et al. [55].

\subsection{Dimensional properties of biscuits}

Table 8 shows the dimensional properties of the fatreplaced biscuits. The diameters of the sample biscuits increased for the 15\% BGF level and then decreased as the level of BGF increased further. The maximum diameter was observed for the $15 \%$ BGF sample, while the diameters for the $10 \%$ BGF and $20 \%$ BGF samples were not significantly $(P \leq 0.05)$ different from the control biscuits. The thickness of biscuits decreased for the 15\% BGF level of fat replacement, similar to results from a study by Arshad et al. [56], for cookies prepared from wheat flour supplemented with defatted wheat germ. However, it was increased significantly $(P \leq 0.05)$ for the $25 \%$ and $50 \%$ BGF samples. Spread ratio is one of the most fundamental properties used in assessing the quality characteristics of cookies [37]. An ideal spread ratio characterizes a superior quality biscuit. BGF at the $15 \%$ level significantly $(P \leq 0.05)$ increased the spread ratio over that of the control biscuit. This unusual result contrasted with those reported from a study by Wekwete and Navder [57], in which avocado puree and Oatrim were used as fat replacers in oatmeal cookies. There are various perspectives on reasons behind decreases in the diameter (aka spread) of biscuits. For example, Agrahar et al. [58] suggested that the rapid distribution of free water to hydrophilic components during the mixing of ingredients led to increased viscosity of the dough, which consequently restricted the spread of biscuits during baking. The current results represented a further indication that BGF has excellent potential for increasing the WAC of biscuit doughs.

\subsection{Textural analysis of biscuits}

Results from a texture profile analysis of the biscuit samples are shown in Table 8. There were significant $(P \leq 0.05)$ differences in hardness $(\mathrm{N})$ among all the biscuit samples. The $50 \%$ BGF biscuit (34.4) showed the highest hardness, followed by the 25\% BGF (26.0) and 20\% BGF (21.4) samples. The lowest hardness values were observed for the $10 \%$ BGF and 15\% BGF biscuits. Hardness is a textural property that attracts significant attention in the evaluation of baked biscuit products in general [37], and often for such products, this parameter should be as low as possible [20]. Hardness, as related to the force required to break a biscuit, increased with the increasing proportion of BGF in the blend with WF. Those increases may have been due to the increasing levels of carbohydrates such as starch and the correspondingly decreasing levels of fat. Another possible reason may have been related to increased water absorption, due to the increasing extent of fat replacement, which could have promoted gluten network development, which in turn would have caused a hardening effect in the biscuits [20]. However, biscuits prepared with the 10\% BGF and 15\% BGF blends showed a remarkably lower-hardness texture profile.
Table 8 Effect of fat replacement by Black gram flour (BGF) on the dimensional properties and breaking force values of sample biscuits

\begin{tabular}{llccc}
\hline Sample & \multicolumn{2}{l}{ Dimensional properties } & \multirow{2}{*}{ Breaking force (N) } \\
\cline { 2 - 4 } & Diameter $(\mathrm{mm})$ & Thickness $(\mathrm{mm})$ & Spread ratio & \\
\hline Control* $^{2}$ & $42.67 \pm 0.24^{\mathrm{c}}$ & $9.07 \pm 0.52^{\mathrm{b}}$ & $4.70 \pm 0.12^{\mathrm{c}}$ & $22.90 \pm 0.39^{\mathrm{d}}$ \\
$10 \%$ BGF & $42.68 \pm 0.27^{\mathrm{c}}$ & $9.09 \pm 0.19^{\mathrm{b}}$ & $4.70 \pm 0.11^{\mathrm{c}}$ & $15.39 \pm 0.10^{\mathrm{a}}$ \\
$15 \%$ BGF & $43.01 \pm 0.54^{\mathrm{d}}$ & $8.07 \pm 0.11^{\mathrm{a}}$ & $5.34 \pm 0.20^{\mathrm{d}}$ & $18.19 \pm 0.15^{\mathrm{b}}$ \\
$20 \%$ BGF & $42.64 \pm 0.32^{\mathrm{c}}$ & $9.19 \pm 0.15^{\mathrm{b}}$ & $4.68 \pm 0.10^{\mathrm{c}}$ & $21.37 \pm 0.13^{\mathrm{c}}$ \\
$25 \%$ BGF & $41.78 \pm 0.13^{\mathrm{b}}$ & $9.37 \pm 0.30^{\mathrm{c}}$ & $4.42 \pm 0.12^{\mathrm{b}}$ & $25.98 \pm 0.57^{\mathrm{e}}$ \\
$50 \%$ BGF & $39.16 \pm 0.16^{\mathrm{a}}$ & $10.45 \pm 0.33^{\mathrm{d}}$ & $3.92 \pm 0.1^{\mathrm{a}}$ & $34.39 \pm 0.25^{\mathrm{f}}$ \\
\hline
\end{tabular}

$a, b, c, d, e, f$ Means followed by different letters in the same column differs significantly $(P \leq 0.05)$. Calculations were made using the Duncan method. Each value is expressed as mean $\pm S D(n=3)$

${ }^{*}$ Control represents biscuits without fat replacement 


\subsection{Color analysis of biscuits}

As shown by the results in Fig. 3, the surface color of the sample biscuits decreased in lightness $\left(L^{*}\right)$ (i.e. progressively darkened) and yellowness $\left(b^{*}\right)$, while increasing in redness $\left(a^{*}\right)$, as the proportion of BGF in the flour blend of the biscuit increased. Similarly, Jan et al. [50] observed decreased $L^{*}$ and $b^{*}$ values and increased $a^{*}$ values for cookies prepared from blends of wheat and buckwheat flours. Such color changes could be explained as being due to browning reactions that would have occurred during baking. Maillard browning and the caramelization of sugar would be expected to produce brown-colored pigments during biscuit baking $[31,59]$. These browning reactions are influenced by many factors, including product moisture content [37], water activity, $\mathrm{pH}$, baking temperature, sugar type, and the composition of amino compounds present [60].

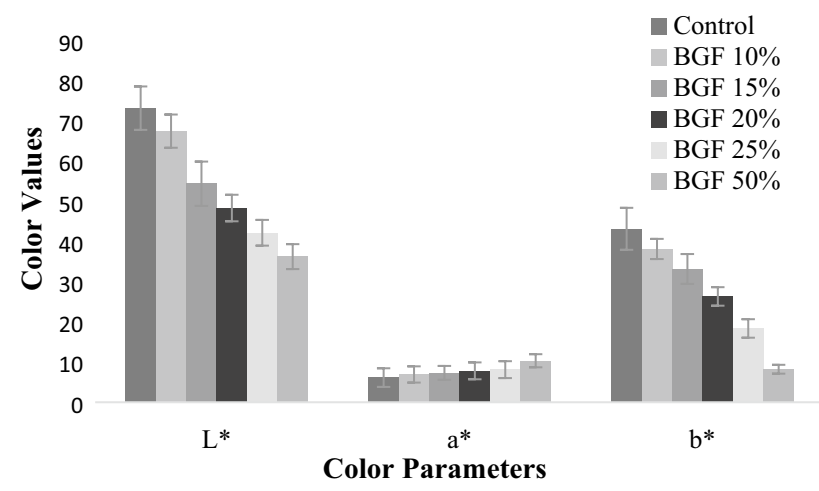

Fig. $3 L^{*}, a^{*}$ and $b^{*}$ values of biscuits made with wheat flour (control) and Black gram flour (BGF) containing blends. Mean indicated by error bars differs significantly $(P \leq 0.05)$. Calculations were made using the Duncan method

\subsection{Nutritional properties of biscuits}

Table 9 shows results for the nutritional properties of the biscuit samples. Fat replacement by BGF led to significantly $(P \leq 0.05)$ increased protein and crude fiber contents, which were attributable to the higher contents of protein and crude fiber in BGF, compared to that of wheat flour. It was observed that protein content increased significantly $(P \leq 0.05)$ for all the BGF-containing biscuits. Although amino acids were not considered in the present study, Tharanathan and Mahadevamma [61] noted that increasing the number of functional ingredients in baked products enhanced the fundamental amino acid profile. According to the World Health Organization (WHO), the recommended dietary allowance (RDA) for protein is $0.8 \mathrm{~g}$ per $\mathrm{kg}$ of body weight for adults and is higher for females during pregnancy and lactation [62]. In contrast to the WF control biscuits (15.20\% protein), protein contents from 20.01 to $26.85 \%$ for the BGF-containing biscuits could contribute to achieving the recommended RDA for protein. Such high-protein biscuit products could also help to reduce acute malnutrition in growing children and women, which is a major concern in Pakistan and other developing nations. As expected, all the BGF-supplemented biscuits contained significantly $(P \leq 0.05)$ more dietary fiber than the traditional, WF control biscuits. Furthermore, all the BGF-WF biscuits were lower in calories than the control, due to the fat replacement and consequent reduction.

\subsection{Sensory analysis of biscuits}

Table 10 shows the sensory scores for the appearance, texture, taste, color, and overall acceptability of the biscuits samples. Fat replacement at the apparently optimum level of $15 \%$ BGF resulted in a sensory score for color, which was significantly $(P \leq 0.05)$ higher than that for the control biscuits. However, that 15\% BGF biscuit sample was not significantly $(P \leq 0.05)$ different or better than the control

Table 9 Nutritional properties of biscuit samples prepared with different levels of Black gram flour (BGF) incorporation

\begin{tabular}{|c|c|c|c|c|c|c|c|}
\hline Samples & Moisture content (\%) & Ash (\%) & Protein (\%) & Fat (\%) & Crude fiber (\%) & Carbohydrates (\%) & $\mathrm{Kcal} / 100 \mathrm{~g}$ \\
\hline Control* & $5.02 \pm 0.12^{c}$ & $1.53 \pm 0.01^{\mathrm{a}}$ & $15.20 \pm 0.10^{a}$ & $27.21 \pm 0.20^{g}$ & $0.21 \pm 0.26 a$ & $50.83 \pm 0.80^{b}$ & 489 \\
\hline $10 \% \mathrm{BGF}$ & $4.20 \pm 0.14^{b}$ & $2.45 \pm 0.03^{b}$ & $20.01 \pm 0.12^{b}$ & $23.41 \pm 0.14^{f}$ & $2.10 \pm 0.20^{\mathrm{b}}$ & $47.83 \pm 0.42^{c}$ & 482 \\
\hline $15 \%$ BGF & $4.31 \pm 0.10^{b}$ & $2.83 \pm 0.01^{c}$ & $23.21 \pm 0.11^{b c}$ & $20.31 \pm 0.10^{\mathrm{e}}$ & $2.33 \pm 0.11^{b}$ & $47.01 \pm 0.57^{d}$ & 463 \\
\hline $20 \%$ BGF & $4.01 \pm 0.11^{a}$ & $4.56 \pm 0.02^{d}$ & $23.75 \pm 0.15^{d}$ & $19.95 \pm 0.21^{d}$ & $2.78 \pm 0.21^{c}$ & $44.95 \pm 0.64^{g}$ & 454 \\
\hline $25 \%$ BGF & $3.92 \pm 0.12^{\mathrm{a}}$ & $4.70 \pm 0.06^{\text {de }}$ & $24.09 \pm 0.20^{\mathrm{de}}$ & $17.51 \pm 0.10^{c}$ & $2.88 \pm 0.13^{\mathrm{cd}}$ & $46.9 \pm 0.60^{\mathrm{e}}$ & 442 \\
\hline $50 \%$ BGF & $3.82 \pm 0.13^{\mathrm{a}}$ & $8.01 \pm 0.09^{e}$ & $26.85 \pm 0.22^{f}$ & $14.71 \pm 0.11^{\mathrm{b}}$ & $3.01 \pm 0.17^{\mathrm{e}}$ & $43.6 \pm 0.54^{f}$ & 414 \\
\hline
\end{tabular}

$a, b, c, d, e, f, g$ Means followed by different letters in the same column differs significantly $(P \leq 0.05)$. Calculations were made using the Duncan method. Each value is expressed as mean $\pm S D(n=3)$

${ }^{*}$ Control represents biscuits without fat replacement 
Table 10 Effect of fat replacement by Black gram flour (BGF) on the sensorial quality of sample biscuits

\begin{tabular}{lllllll}
\hline Sample & Appearance $\left(9^{*}\right)$ & Taste $\left(9^{*}\right)$ & Texture $\left(9^{*}\right)$ & Color $\left(9^{*}\right)$ & $\begin{array}{l}\text { Overall } \\
\text { acceptabil- } \\
\text { ity }\left(9^{*}\right)\end{array}$ & Overall sum (45) \\
\hline Control1 & $8.20 \pm 0.12^{\mathrm{c}}$ & $8.27 \pm 0.31^{\mathrm{e}}$ & $8.27 \pm 0.14^{\mathrm{e}}$ & $7.11 \pm 0.03^{\mathrm{c}}$ & $8.04 \pm 0.04^{\mathrm{d}}$ & 39.89 \\
$10 \%$ BGF & $7.14 \pm 0.15^{\mathrm{b}}$ & $7.06 \pm 0.50^{\mathrm{d}}$ & $8.06 \pm 0.15^{\mathrm{d}}$ & $8.03 \pm 0.05^{\mathrm{d}}$ & $8.00 \pm 0.04^{\mathrm{d}}$ & 38.29 \\
$15 \%$ BGF & $8.21 \pm 0.11^{\mathrm{c}}$ & $8.30 \pm 0.42^{\mathrm{e}}$ & $8.20 \pm 0.17^{\mathrm{d}, \mathrm{e}}$ & $8.9 \pm 0.11^{\mathrm{e}}$ & $8.06 \pm 0.05^{\mathrm{d}}$ & 41.67 \\
$20 \%$ BGF & $7.14 \pm 0.12^{\mathrm{b}}$ & $6.16 \pm 0.11^{\mathrm{c}}$ & $6.06 \pm 0.16^{\mathrm{c}}$ & $7.09 \pm 0.06^{\mathrm{c}}$ & $6.14 \pm 0.03^{\mathrm{c}}$ & 32.59 \\
$25 \%$ BGF & $7.13 \pm 0.16^{\mathrm{b}}$ & $5.10 \pm 0.10^{\mathrm{b}}$ & $4.26 \pm 0.25^{\mathrm{b}}$ & $5.32 \pm 0.17^{\mathrm{b}}$ & $5.32 \pm 0.02^{\mathrm{b}}$ & 27.13 \\
$50 \%$ BGF & $5.12 \pm 0.10^{\mathrm{a}}$ & $4.23 \pm 0.14^{\mathrm{a}}$ & $3.11 \pm 0.11^{\mathrm{a}}$ & $4.31 \pm 0.15^{\mathrm{a}}$ & $5.11 \pm 0.01^{\mathrm{a}}$ & 21.88 \\
\hline
\end{tabular}

$a, b, c, d$ Means followed by different letters in the same column differs significantly $(P \leq 0.05)$. Calculations were made using the Duncan method. Each value is expressed as mean $\pm S D(n=3)$

*9 points hedonic scale: 9; like extremely, 8; like very musk, 7; like moderately, 6; like slightly, 5; neither like nor dislike, 4; dislike slightly, 3; dislike moderately, 2; dislike very much, 1; dislike extremely

${ }^{1}$ Control represents biscuits without fat replacement in terms of appearance, taste, texture, and overall acceptability. Moreover, the control, 10\% BGF, and 15\% BGF biscuits did not differ significantly $(P \leq 0.05)$ for overall acceptability (Fig. 4). As the extent of fat replacement increased beyond the 15\% BGF level, the score for taste, which is one of the essential sensory attributes of the biscuits, decreased, due to an unpleasant mouthfeel, and to the increased hardness of the biscuits. In fact, the textures of the 20\% BGF and 25\% BGF biscuit samples were too hard and firm. These negative results were apparently due to an excessive reduction in the level of actual fat in the biscuit formulas, as fat is known to help "moisturize" the structure and soften the texture of many types of baked goods, thus providing such food products with consumer-demanded textural properties [4]. Singh et al. [63] had shown that incorporation of $15 \%$ of a legumes mixture (Bengal gram, black gram, green gram) into wheat flour, for the production of high-protein biscuits, negatively affected product top-grain, color, and texture. In contrast, in the present study, biscuit top-grain was unaffected.

\subsection{Principal component analysis (PCA)}

PCA was used, as illustrated in Fig. 3 to examine the interrelationships among the physicochemical properties, bioactive compounds, and rheological characteristics of the control WF and the five BGF-WF blends. Principal component 1 (PC1) and principal component 2 (PC2), cumulatively, explained $91.38 \%$ of the total variation among the 23 attributes of the six flour samples. PC1 had an eigenvalue of 16.3 and accounted for $68.01 \%$ of the variation in the data, whereas PC2 accounted for $23.37 \%$
Fig. 4 Images of biscuit samples (a) Biscuit without fat replacement (b) Biscuit with Black gram flour (BGF) $10 \%$ (c) BGF $15 \%$, (d) BGF 20\%, (e) BGF $25 \%$ and (f) BGF $50 \%$

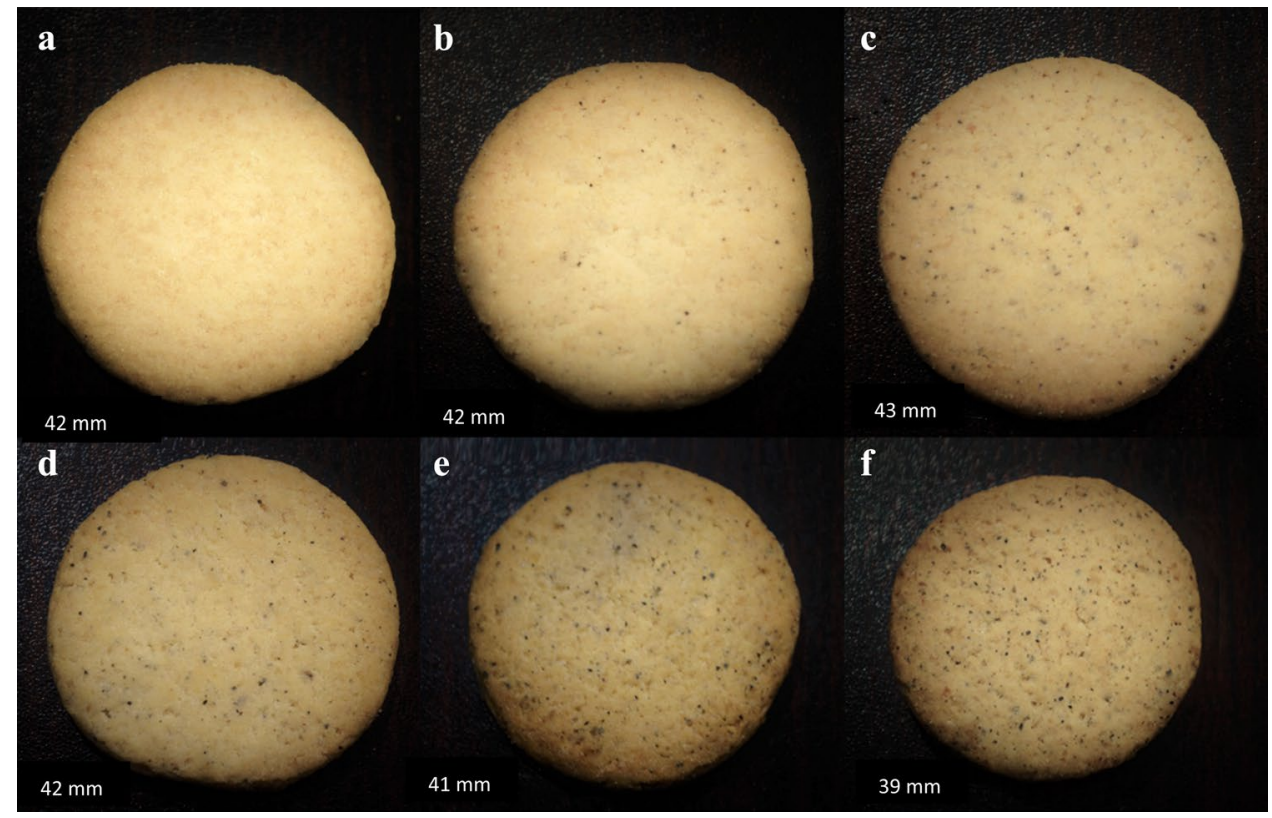


Biplot (axes PC1 and PC2: $91.38 \%$ )

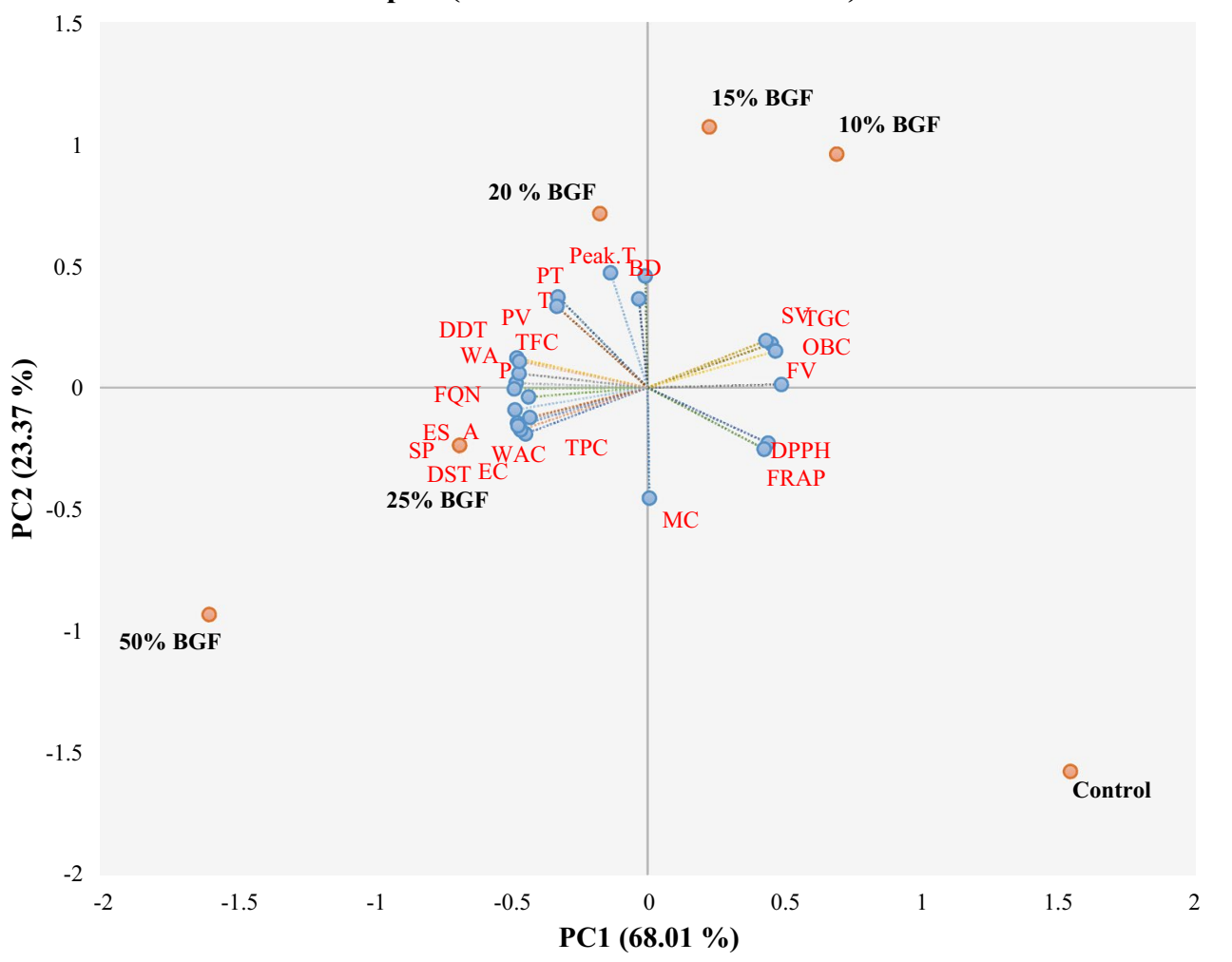

Fig. 5 The principal component analysis (PCA) score plot of flour samples at different properties (proximate, functional, rheological, antioxidants, and phytochemicals). Where, PC1 principal component analysis $1, P C 2$ principal component analysis $2, M C$ Moisture content (\%), $A$ ash (\%), $P$ protein (\%), DG dry gluten (\%), WG wet gluten (\%), Gl gluten index, TGC total gluten content (\%), SP swelling power $\left(\mathrm{g} \mathrm{g}^{-1}\right), W A C$ water absorption capacity (\%), OBC oil binding capacity (\%), EC emulsion capacity (\%), ES emulsion stability

of the variation in the data. The 10\% BGF, 15\% BGF, $20 \%$ BGF, and $25 \%$ BGF sample blends were observed to be positively correlated with each other, as the $10 \%$ BGF and $15 \%$ BGF samples fell in the same quadrant. Moreover, the $15 \%$ BGF and $20 \%$ BGF samples appeared to lie close to each other in the bi-plot. In contrast, the WF control and the $50 \%$ BGF sample were observed to be opposite to each other in the bi-plot, thus establishing a negative correlation. Furthermore, the $25 \%$ BGF and $50 \%$ BGF samples demonstrated a positive correlation, as they were located in the same quadrant. The bi-plot of PC1 vs. PC2 showed that maximum attributes were associated with PC1. For PC1, a positive relationship could be observed among physicochemical attributes (ash \%, total gluten content $\%$, and moisture content \%), rheological properties (final and setback viscosities), and antioxidant activities (DPPH inhibition and FRAP). PC2 correlated positively with DDT, peak viscosity, breakdown viscosity, trough, peak time, pasting temperature, OBC \%, protein \%, and TFC. However, DST,
(\%), WA water absorption (\%), DDT dough development time (min), $D S T$ dough stability time (min), FQN farinograph quality number, $P V$ peak viscosity (Torque), FV final viscosity (Torque), SV setback viscosity (Torque), BD break down (Torque), Peak.T peak time (min), PT pasting temperature $\left({ }^{\circ} \mathrm{C}\right), D P P H D P P H$-inhibition $\left(\mathrm{IC}_{50} \mathrm{mg} \mathrm{mL}^{-1}\right)$, FRAP Ferric reducing antioxidant power $\left(\mathrm{IC}_{50} \mathrm{mg} \mathrm{mL}^{-1}\right), T P C$ total phenolic content (mg Gallic acid equivalent/100 $\mathrm{g}$ dry weight), TFC total flavonoid content (mg Catechin equivalent /100 g dry weight)

FQN, WAC \%, SP, EC \%, ES \%, and TPC contributed negatively to the variations among the flour blend samples. The distinct position of the WF control apparently accounted for the negative correlation, and also suggested its strong influence on rheological, functional, proximate, and antioxidant properties (Fig. 5).

\subsection{Conclusion}

The fat-replaced biscuits and their corresponding flour blends, prepared by incorporating increasing levels of black gram flour (BGF) (10 to 50\%) into the control WF, showed increased total phenolic content, total flavonoid content, and DPPH inhibition, compared to that for the control biscuits. Dough rheological analysis demonstrated that the increased additions of BGF into the WF control caused no significant undesirable effects on the functional properties of the wheat flour. Furthermore, functional properties of the BGF-WF blends, including 
water-absorption capacity, oil-binding capacity, emulsion capacity, and emulsion stability, were increased, some of which suggested the potential benefit of the utilization of BGF as a fat replacer in baked products such as biscuit. Fat replacement at a 15\% BGF level in biscuits resulted in overall excellent quality and sensory attributes, but sensory acceptability declined beyond this $15 \%$ fat-replacement level. Additional studies are needed in the future, to improve further the functional behavior of BGF as a fat replacer, and the resulting quality of BGF-containing biscuits.

Acknowledgements The help of Ms. Uroosa Ejaz and Syed Faizan Ali in proof reading of this manuscript is acknowledged. The authors are grateful to the University of Karachi for partial funding through a Dean Research Grant, and to English Biscuit Manufacturers management, particularly Dr. Zeelaf Munir and Madam Saadia Naveed, for their encouragement and support. The authors are also thankful to Mr. Yousuf, Centralized Science Laboratory, University of Karachi, for his assistance in the SEM study of dough structure, and to Dr. Harry Levine, Food Polymer Science Consultancy, USA, for his review and editing of a pre-submittal draft of this manuscript.

\section{Compliance with ethical standards}

Conflict of interest The authors declare that they have no competing interests.

Human and animal rights This article does not contain any In Vivo studies with human participants (except biscuits sensory test) or animals performed by any of the authors.

\section{References}

1. Shandilya U, Sharma A (2017) Functional foods and their benefits: an overview. J Nutr Health Food Eng 7:247

2. Zia-Ul-Haq M, Ahmad S, Bukhari SA, Amarowicz R, Ercisli S, Jaafar HZ (2014) Compositional studies and biological activities of some mash bean (Vigna mungo (L.) Hepper) cultivars commonly consumed in Pakistan. Bio Resh 47:23

3. Rodriguez García J, Puig A, Salvador A, Hernando I (2012) Optimization of a sponge cake formulation with inulin as fat replacer: structure, physicochemical, and sensory properties. J Food Sci 77:189-197

4. Mamat H, Hill SE (2014) Effect of fat types on the structural and textural properties of dough and semi-sweet biscuit. J Food Sci Technol 51:1998-2005

5. Frye AM, Setser CS (1993) Bulking agents and fat substitutes. In: Altschul AM (ed) Low calorie foods handbook. Marcel Dekker, New York, pp 1-52

6. Yackel WC, Cox C (1992) Application of starch-based fat replacers. Food Technol 46:146-148

7. Lucca PA, Tepper BJ (1994) Fat replacers and the functionality of fat in foods. Trends Food Sci Technol 5:12-19. https://doi. org/10.1016/0924-2244(94)90043-4

8. Akoh CC (1998) Fat replacers. Food Technol 52(3):47-53

9. Wani IA, Sogi DS, Gill BS (2013) Physicochemical and functional properties of flours from three Black gram (Phaseolus mungo
L.) cultivars. Int Food Sci Technol 48(4):771-777. https://doi. org/10.1111/ijfs.12025

10. O'Connor TP, O'Brien NM (2016) Fat replacers. In: Reference module in food science. Elsevier, Amsterdam. https://doi. org/10.1016/B978-0-08-100596-5.00648-X

11. Yemenicioglu A, Farris S, Turkyilmaz M, Gulec S (2019) A review of current and future food applications of natural hydrocolloids. Int Food Sci Technol 55(4):1389-1406. https://doi.org/10.1111/ ijfs.14363

12. Román L, Santos I, Martínez MM, Gómez M (2015) Effect of extruded wheat flour as a fat replacer on batter characteristics and cake quality. J Food Sci Technol 52:8188-8195

13. Sudha M, Srivastava A, Vetrimani R, Leelavathi K (2007) Fat replacement in soft dough biscuits: Its implications on dough rheology and biscuit quality. J Food Eng 80:922-930

14. Adair M, Knight S, Gates G (2001) Acceptability of peanut butter cookies prepared using mungbean paste as a fat ingredient substitute. J Am Diet Assoc 101:467-469

15. Rankin LL, Bingham M (2000) Acceptability of oatmeal chocolate chip cookies prepared using pureed white beans as a fat ingredient substitute. J Acad Nutr Diet 100:831

16. Ajila CJ, Rao UJSP (2009) Purification and characterization of black gram (Vigna mungo) husk peroxidase. J Mol Catal B: Enzym 60:36-44

17. AACC (2000) Approved Methods of the American Association of Cereal Chemists. AACC, St. Paul, MN

18. Abebe W, Collar C, Ronda F (2015) Impact of variety type and particle size distribution on starch enzymatic hydrolysis and functional properties of tef flours. Carbohydr Polym 115:260-268

19. Yasumatsu K, Sawada K, Moritaka S, Misaki M, Toda J, Wada T, Ishii K (1972) Whipping and emulsifying properties of soybean products. Agric Biol Chem 36:719-727

20. Ali R, Saeed SMG, Ali SA, Sayed SA, Ahmed R, Mobin L (2018) Effect of black gram flour as egg replacer on microstructure of biscuit dough and its impact on edible qualities. J Food Meas Charact 12:1641-1647

21. Sayas-Barberá E, Martín-Sánchez AM, Cherif S, Ben-Abda J, Pérez-Álvarez JÁ (2020) Effect of date (Phoenix dactylifera L.) pits on the shelf life of beef burgers. Foods 9:102

22. Fan H, Zheng T, Chen Y, Yang G-Z (2012) Chemical constituents with free-radical-scavenging activities from the stem of Fissistigma polyanthum. Pharmacol Mag 8:98

23. Oyaizu M (1986) Studies on products of browning reactions: Antioxidative activities of products of browning reaction prepared from glucosamine. Jpn J Nutr 44:307-315

24. Gawlik-Dziki U, Swieca M, Dziki D, Sęczyk L, Zlotek U, Rozylo R, Czyz J (2014) Anticancer and antioxidant activity of bread enriched with broccoli sprouts. BioMed Res Int 2014:608053. https://doi.org/10.1155/2014/608053

25. Salar RK, Purewal SS (2017) Phenolic content, antioxidant potential and DNA damage protection of pearl millet (Pennisetum glaucum) cultivars of North Indian region. J Food Meas Charact 11:126-133

26. Dewanto V, Wu X, Liu RH (2002) Processed sweet corn has higher antioxidant activity. J Agric Food Chem 50:4959-4964

27. Ohizua ER, Adeola AA, Idowu MA, Sobukola OP, Afolabi TA, Ishola RO et al (2017) Nutrient composition, functional, and pasting properties of unripe cooking banana, pigeon pea, and sweet potato flour blends. Food Sci Nutr 5:750-762

28. Lawless HT, Heymann H (2010) Sensory evaluation of food principles and practices, descriptive analysis, 2 nd edn. Springer Science \& Business Media, Berlin, pp 378-441

29. Ocheme OB, Adedeji OE, Chinma CE, Yakubu CM, Ajibo UH (2018) Proximate composition, functional, and pasting 
properties of wheat and groundnut protein concentrate flour blends. Food Sci Nutr 6(5):1173-1178. https://doi.org/10.1002/ fsn 3.670

30. Klunklin W, Savage G (2018) Physicochemical properties and sensory evaluation of wheat-purple rice biscuits enriched with green-lipped mussel powder (Perna canaliculus)v and spices. J Food Qual 2018:7697903 doi.org/10.1155/2018/7697903

31. Colla K, Costanzo A, Gamlath S (2018) Fat replacers in baked food products. Foods 7(1):192. https://doi.org/10.3390/foods 7120192

32. Chandra S, Singh S, Kumari D (2015) Evaluation of functional properties of composite flours and sensorial attributes of composite flour biscuits. J Food Sci Technol 52:3681-3688

33. Kaur M, Singh N (2007) Characterization of protein isolates from different Indian chickpea (Cicer arietinum L.) cultivars. Food Chem 102:366-374

34. Kuntz ID (1971) Hydration of macromolecules. III Hydration of polypeptides. J Am Chem Soc 93:514-516

35. Patel AR, Nicholson RA, Marangoni AG (2020) Applications of Fat mimetics for the replacement of saturated and hydrogenated fat in food products. Curr Opin Food Sci 33:61-68

36. Graham DE, Phillips MC (1976) The conformation of proteins at the air-water interface and their role in stabilizing foams. In: Akers RJ (ed) Foams. Academic Press, New York, p 131

37. Kweon M, Slade L, Levine H (2011) Solvent retention capacity (SRC) testing of wheat flour: Principles and value in predicting flour functionality in different wheat-based food processes, as well as in wheat breeding - a review. Cereal Chem 88:537-552

38. Portman D, Blanchard C, Maharjan P, McDonald LS, Mawson J, Naiker M, Panozzo JF (2018) Blending studies using wheat and lentil cotyledon flour-effects on rheology and bread quality. Cereal Chem 95:849-860

39. Issarny C, Cao W, Falk D, Seetharaman K, Bock JE (2017) Exploring functionality of hard and soft wheat flour blends for improved end use quality prediction. Cereal Chem 94:723-732

40. Turfani V, Narducci V, Durazzo A, Galli V, Carcea M (2017) Technological, nutritional and functional properties of wheat bread enriched with lentil or carob flours. LWT Food Sci Technol 78:361-366

41. Bae W, Lee B, Hou GG, Lee S (2014) Physicochemical characterization of whole-grain wheat flour in a frozen dough system for bake off technology. J Cereal Sci 60:520-525

42. Wang S, Li C, Copeland L, Niu Q, Wang S (2015) Starch retrogradation: a comprehensive review. Comp Rev Food Sci Food Saf 14:568-585

43. Gomez M, Oliete B, Rosell CM, Pando V, Fernández E (2008) Studies on cake quality made of wheat-chickpea flour blends. LWT Food Sci Technol 41:1701-1709

44. Yaqoob S, Cai D, Liu M, Zheng M, Zhao CB, Liu JS (2019) Characterization of microstructure, physicochemical and functional properties of corn varieties using different analytical techniques. Int J Food Prop 22:572-582

45. Faridi H, Faubion JM (1994) Microstructure of cookies, crackers, and their doughs. In: Faridi $\mathrm{H}$ (ed) The science of cookie and cracker production. Chapman and Hall, New York, pp 150-160

46. Madhumitha S, Prabhasankar P (2011) Influence of additives on functional and nutritional quality characteristics of black gram flour incorporated pasta. J Text Stud 42:441-450

47. Dachana K, Rajiv J, Indrani D, Prakash J (2010) Effect of dried moringa (Moringa oleifera lam) leaves on rheological, microstructural, nutritional, textural and organoleptic characteristics of cookies. J Food Qual 33:660-677

48. Sharma P, Gujral HS (2014) Cookie making behavior of wheatbarley flour blends and effects on antioxidant properties. LWT Food Sci Technol 55:301-307

49. Manzocco L, Calligaris S, Mastrocola D, Nicoli MC, Lerici CR (2000) Review of non-enzymatic browning and antioxidant capacity in processed foods. Trends Food Sci Technol 11:340-346

50. Jan U, Gani A, Ahmad M, Shah U, Baba WN, Masoodi F, Wani $S$ (2015) Characterization of cookies made from wheat flour blended with buckwheat flour and effect on antioxidant properties. J Food Sci Technol 52:6334-6344

51. Carbonaro M (2011) Role of pulses in nutraceuticals. In: Pulse foods: processing, quality and nutraceutical applications, 1st edn. Elsevier, London, pp 385-418

52. Sibul F, Orcic D, Vasic M, Anackov G, Nadpal J, Savic A, MimicaDukic N (2016) Phenolic profile, antioxidant and anti-inflammatory potential of herb and root extracts of seven selected legumes. Ind Crop Prod 83:641-653

53. Scalbert A, Manach C, Morand C, Remesy C (2005) Dietary polyphenols and the prevention of diseases. Crit Rev Food Sci Nutr 45:287-306

54. Mahloko LM, Silungwe $H$, Mashau ME, Kgatla TE (2019) Bioactive compounds, antioxidant activity and physical characteristics of wheat-prickly pear and banana biscuits. Heliyon 5:e02479. https ://doi.org/10.1016/j.heliyon.2019.e02479

55. Oboh G, Puntel RL, Rocha JBT (2007) Hot pepper (Capsicum annuum, Tepin and Capsicum chinese, Habanero) prevents Fe2+-induced lipid peroxidation in Brain- in vitro. Food Chem 102:178-185

56. Arshad MU, Anjum FM, Zahoor T (2007) Nutritional assessment of cookies supplemented with defatted wheat germ. Food Chem 102:123-128

57. Wekwete B, Navder KP (2008) Effects of avocado fruit puree and oatrim as fat replacers on the physical, textural and sensory properties of oatmeal cookies. J Food Qual 31:131-141

58. Agrahar-Murugkar D, Gulati P, Kotwaliwale N, Gupta C (2015) Evaluation of nutritional, textural and particle size characteristics of dough and biscuits made from composite flours containing sprouted and malted ingredients. J Food Sci Technol 52:5129-5137

59. Laguna L, Salvador A, Sanz T, Fiszman SM (2011) Performance of a resistant starch rich ingredient in the baking and eating quality of short-dough biscuits. LWT Food Sci Technol 44:737-746

60. Sharma P, Gujral HS (2013) Extrusion of hulled barley affecting $\beta$-glucan and properties of extrudates. Food Bioproc Tech 6:1374-1389

61. Tharanathan RN, Mahadevamma S (2003) Grain legumes-a boon to human nutrition. Trends Food Sci Technol 14:507-518

62. US Department of Agriculture, A. R. S, USDA (2015) National nutrient database for standard reference. In: Release

63. Singh B, Bajaj M, Kaur A, Sharma S, Sidhu J (1993) Studies on the development of high-protein biscuits from composite flours. Plant Foods Hum Nutr 43:181-189

Publisher's Note Springer Nature remains neutral with regard to jurisdictional claims in published maps and institutional affiliations. 